\title{
ADVANCED FINE PARTICULATE CHARACTERIZATION METHODS
}

\section{Final Report}

(for the period April 1, 2004, through January 31, 2007)

Prepared for:

AAD Document Control

U.S. Department of Energy

National Energy Technology Laboratory

626 Cochrans Mill Road

PO Box 10940, MS 921-107

Pittsburgh, PA 15236-0940

Cooperative Agreement No. DE-FC26-98FT40320

Performance Monitor: Sara Pletcher

Prepared by:

Steven A. Benson

Lingbu Kong

Kurt E. Eylands

Alexander Azenkeng

Jason D. Laumb

Robert R. Jensen

Edwin S. Olson

Jill M. Mackenzie

A.M. Rokanuzzaman

Energy \& Environmental Research Center University of North Dakota 15 North 23rd Street, Stop 9018

Grand Forks, ND 58202-9018

Mark R. Hoffmann ${ }^{1}$ Alena Kubátová ${ }^{1}$ Artur Braun $^{2}$

${ }^{1}$ Department of Chemistry, University of North Dakota, Grand Forks, ND ${ }^{2}$ Department of Chemical \& Materials Engineering, Consortium for Fossil Fuel Science University of Kentucky, Lexington, KY 


\section{EERC DISCLAIMER}

LEGAL NOTICE This research report was prepared by the Energy \& Environmental Research Center (EERC), an agency of the University of North Dakota, as an account of work sponsored by U.S. Department of Energy. Because of the research nature of the work performed, neither the EERC nor any of its employees makes any warranty, express or implied, or assumes any legal liability or responsibility for the accuracy, completeness, or usefulness of any information, apparatus, product, or process disclosed or represents that its use would not infringe privately owned rights. Reference herein to any specific commercial product, process, or service by trade name, trademark, manufacturer, or otherwise does not necessarily constitute or imply its endorsement or recommendation by the EERC.

\section{DISCLAIMER}

This report was prepared as an account of work sponsored by an agency of the United States Government. Neither the United States Government, nor any agency thereof, nor any of their employees makes any warranty, express or implied, or assumes any legal liability or responsibility for the accuracy, completeness, or usefulness of any information, apparatus, product, or process disclosed or represents that its use would not infringe privately owned rights. Reference herein to any specific commercial product, process, or service by trade name, trademark, manufacturer, or otherwise does not necessarily constitute or imply its endorsement, recommendation, or favoring by the United States Government or any agency thereof. The views and opinions of authors expressed herein do not necessarily state or reflect those of the United States Government or any agency thereof.

This report is available to the public from the National Technical Information Service, U.S. Department of Commerce, 5285 Port Royal Road, Springfield, VA 22161; phone orders accepted at (703) 487-4650. 


\title{
BASE SUBTASK 2.10 ADVANCED FINE PARTICULATE CHARACTERIZATION
}

\begin{abstract}
The characterization and control of emissions from combustion sources are of significant importance in improving local and regional air quality. Such emissions include fine particulate matter, organic carbon compounds, and $\mathrm{NO}_{\mathrm{x}}$ and $\mathrm{SO}_{2}$ gases, along with mercury and other toxic metals. This project involved four activities including Further Development of Analytical Techniques for $\mathrm{PM}_{10}$ and $\mathrm{PM}_{2.5}$ Characterization and Source Apportionment and Management, Organic Carbonaceous Particulate and Metal Speciation for Source Apportionment Studies, Quantum Modeling, and High-Potassium Carbon Production with Biomass-Coal Blending. The key accomplishments included the development of improved automated methods to characterize the inorganic and organic components' particulate matter. The methods involved the use of scanning electron microscopy and x-ray microanalysis for the inorganic fraction and a combination of extractive methods combined with near-edge x-ray absorption fine structure to characterize the organic fraction. These methods have direction application for source apportionment studies of PM because they provide detailed inorganic analysis along with total organic and elemental carbon $(\mathrm{OC} / \mathrm{EC})$ quantification.

Quantum modeling using density functional theory (DFT) calculations was used to further elucidate a recently developed mechanistic model for mercury speciation in coal combustion systems and interactions on activated carbon. Reaction energies, enthalpies, free energies and binding energies of $\mathrm{Hg}$ species to the prototype molecules were derived from the data obtained in these calculations. Bimolecular rate constants for the various elementary steps in the mechanism have been estimated using the hard-sphere collision theory approximation, and the results seem to indicate that extremely fast kinetics could be involved in these surface reactions. Activated carbon was produced from a blend of lignite coal from the Center Mine in North Dakota and sunflower hulls for the biomass material to be carbonized. The ability to remove mercury from a bituminous coal's derived flue gas was low. Removals of only $15 \%$ were attained while injecting $6 \mathrm{lb} / \mathrm{Macf}$ of activated carbon upstream of an electrostatic precipitator. Poisoning of sites on the activated carbon by $\mathrm{SO}_{2}$ and $\mathrm{SO}_{3}$ contributed to the poor mercury capture performance.
\end{abstract}




\section{TABLE OF CONTENTS}

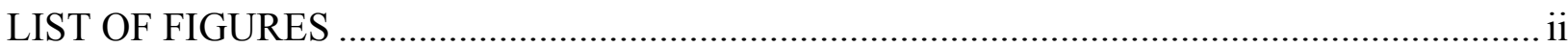

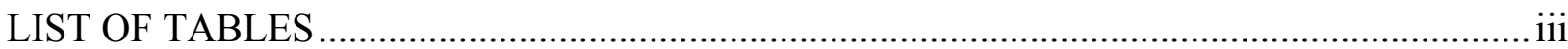

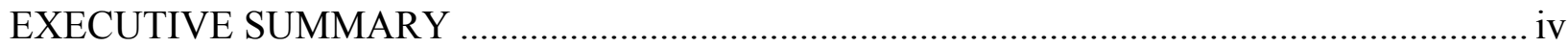

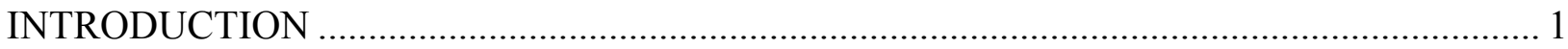

Activity 1: Further Development of Analytical Techniques for $\mathrm{PM}_{10}$ and $\mathrm{PM}_{2.5}$

Characterization and Source Apportionment and Management........................................... 1

Activity 2: Organic Carbonaceous Particulate and Metal Speciation for Source

Apportionment Studies............................................................................................... 1

Activity 3: Quantum Mechanical Modeling of Mercury Speciation in Coal Combustion

Systems and Interactions on Activated Carbon................................................................ 2

Activity 4: High-Potassium Carbon Production with Biomass-Coal Blending ................... 2

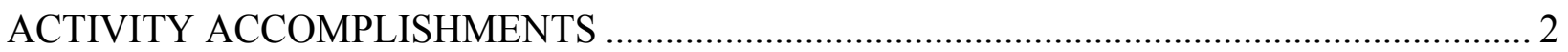

Activity 1: Further Development of Analytical Techniques for $\mathrm{PM}_{10}$ and $\mathrm{PM}_{2.5}$

Characterization and Source Appointment and Management................................................ 2

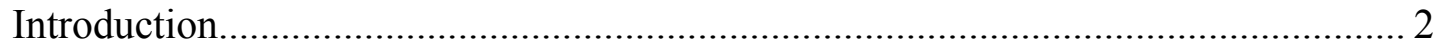

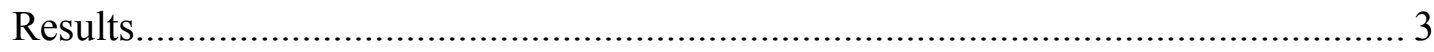

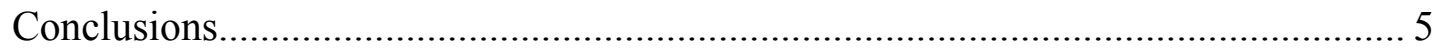

Activity 2: Organic Carbonaceous Particulate and Metal Speciation for Source

Apportionment Studies................................................................................................. 7

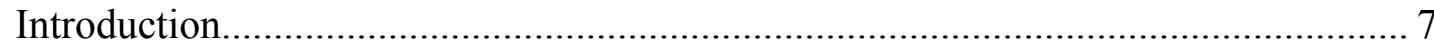

Experimental Results and Discussion............................................................ 8

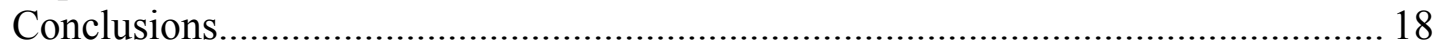

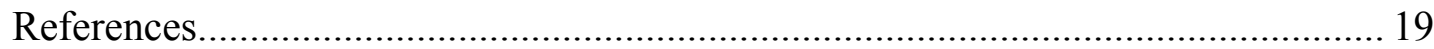

Activity 3: Quantum Mechanical Modeling of Mercury Speciation in Coal Combustion Systems and Interactions on Activated Carbon................................................................. 20

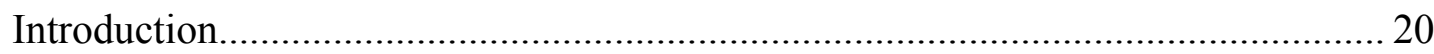

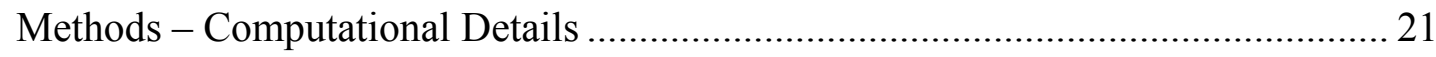

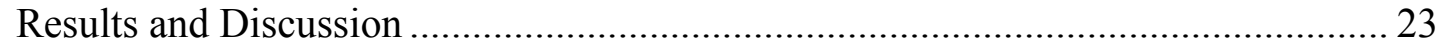

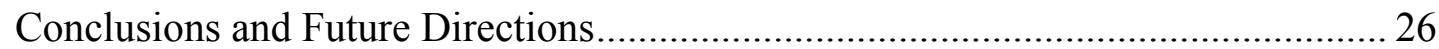

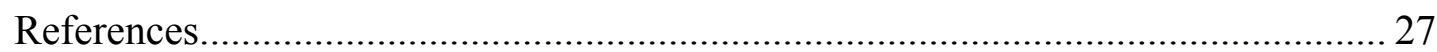

Activity 4: High-Potassium Carbon Production with Biomass-Coal Blending ................. 28

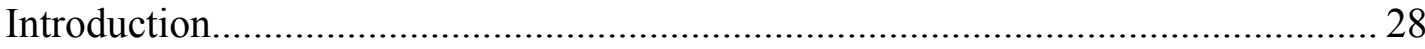

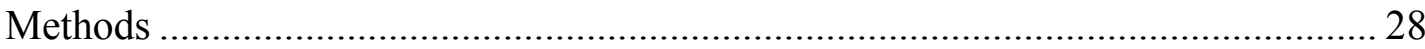

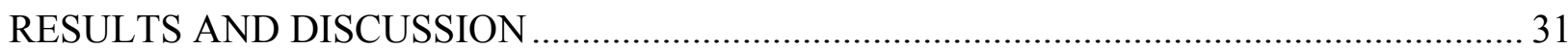




\section{LIST OF FIGURES}

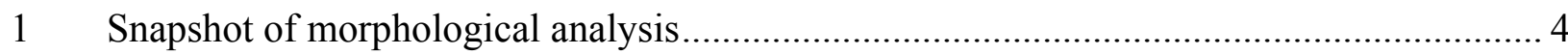

2 Backscattered electron image of an ash sample with numbered points analyzed ................. 4

3 Particle-size distribution of fine particulate collected downstream of an ESP and

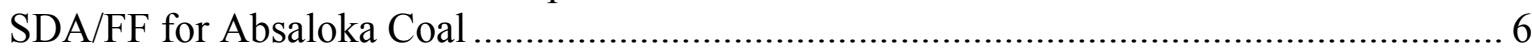

4 Particle-size distribution of fine particulate collected downstream of an ESP, SDA/ESP, and SDA/FF for Caballo coal combustion $\mathrm{PM}_{2.5}$ testing ………………............................. 6

5 The effect of flow rate on the OC recoveries extracted from 50-mg portions of PM samples using sequential hot pressurized water extraction ................................................. 11

6 Comparison of mass extracted from wood smoke and diesel exhaust PM using different solvents

7 Comparison of OC extraction efficiency based on EC/OC ratio from different types of PM using hot pressurized water ............................................................................... 13

8 Polar and midpolarity OC extracted with HPW directly and after the Soxhlet extraction with methylene chloride ………………………….......................................... 14

9 The OC content in PM samples and OC wt\% of extracted with HPW/steam...................... 14

10 Distribution of different polarity OC determined using HPW extraction in PM samples

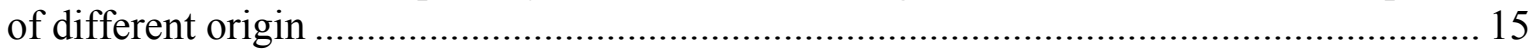

11 NEXAFS spectra differentiation of different carbon functional groups based on resonance energy

12 NEXAFS spectra of polar and midpolarity fractions obtained with HPW at different

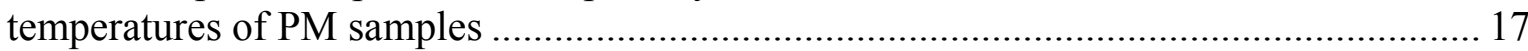

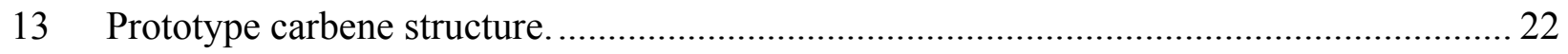

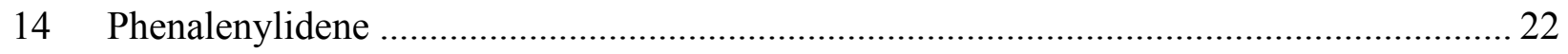

15 Plot of energy changes for proton attachment with molecule size...................................... 24

16 Plot of energy changes for the attachment of $\mathrm{Hg}^{0}$ with molecule size...............................2 24

Continued. . . 


\section{LIST OF FIGURES (continued)}

17 Plot of energy changes for the capture of $\mathrm{Cl}^{-}$with molecule size .................................. 25

18 Plot of K, BE with molecule size ........................................................................... 25

19 Plot of rate constants with molecule size .............................................................. 26

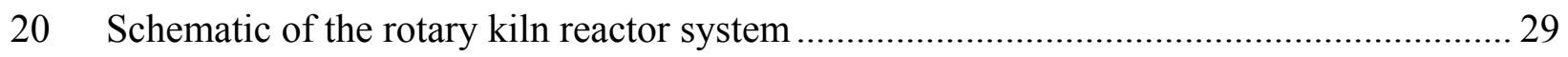

21 The rotary kiln reactor system installed in the EERC pilot plant................................... 29

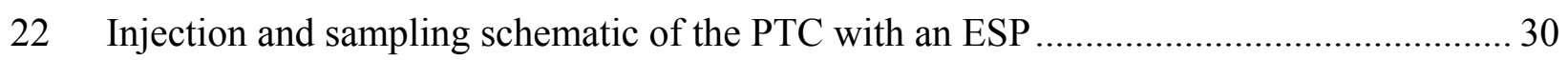

\section{LIST OF TABLES}

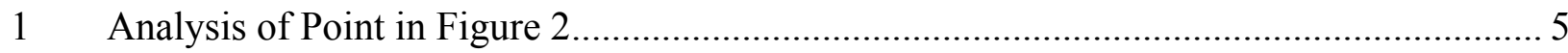

2 Experimental Conditions Employed for Extraction of Carbonaceous PM ....................... 8

$3 \quad$ Inorganics Extracted with Ambient Water........................................................... 17

4 Distribution of Sulfate in Fractions Extracted with Hot Pressurized Water ..................... 18 


\section{BASE SUBTASK 2.10 ADVANCED FINE PARTICULATE CHARACTERIZATION}

\section{EXECUTIVE SUMMARY}

\section{Activity 1: Further Development of Analytical Techniques for $\mathbf{P M}_{10}$ and $\mathbf{P M}_{2.5}$ Characterization and Source Apportionment and Management}

A software application for the WinEDS has been developed for morphology analysis. With this new software, semiautomated point analysis and reporting can be performed. The analysis report combines the scanning electron microscopy (SEM) images with the point analysis into a single document for printing or editing by Microsoft Word. This new morphology software can also export Excel files.

Particulate samples produced from a subbituminous coal from the Powder River Basin were collected downstream of various control technologies and characterized by the Energy \& Environmental Research Center's (EERC's) automated SEM techniques. The primary component present in the spray dryer absorber/electrostatic precipitator (SDA/ESP) was calcium with a minor amount of sodium associated with phosphorus and sulfur species. The primary components found downstream of the SDA/FF were rich in calcium. The ESP/baghouse had a very small amount of calcium-rich particles. The ESP only had more particles, and in addition to the calcium sulfate-type particles, the sample contained some alumninosilicates.

\section{Activity 2: Organic Carbonaceous Particulate and Metal Speciation for Source Apportionment Studies}

Source apportionment studies of particulate matter (PM) are based on detailed inorganic analysis along with total organic and elemental carbon (OC/EC) quantification. The single OC number is normally employed because the analytical studies necessary for the quantification of hundreds of extractable organics are too time-consuming and costly. The frequently used OC/EC determination which reduces all organics to a single number underestimates the importance of organics in PM. Additionally, the OC/EC determination is limited to identification of the "split" between organic and elemental carbon, which is still analyst-dependent. Similarly, metal determinations are typically focused on their total content in PM. Although the toxicity of watersoluble metals (selected species) has been shown, not much attention has been paid to their speciation because of the analytical complexity. Water and organic solvents (if employed sequentially or in a mixture) are capable of extracting organic PM constituents. The advantage of water is its ability to extract ionic species (metals, sulfates, etc.) as well as a wide polarity range of organic PM constituents. While nonpolar organics such as polycyclic aromatic hydrocarbon (PAHs) are associated with primary emissions, the contribution from polar, oxygenated species such as aldehydes, organic nitrates, and mono- and dicarboxylic acids are related to secondary aerosol formation. The measurement of water-soluble, polar, and nonpolar constituents of PM is important to both source apportionment and determination of toxicological impacts. Their fractionation and analysis will provide for a significant advance in characterizing fine particulates. 
In this work, hot pressurized water for fractionation of $\mathrm{OC}$ for source apportionment studies has been used. Four OC fractions obtained were polar extracted by ambient (bioavailable and secondary OC), midpolarity (secondary OC), and nonpolar (primary OC). Those fractions were further characterized using near-edge $\mathrm{x}$-ray absorption fine structure (NEXAFS) spectroscopy. In addition, we have attempted to develop a method for determination of inorganics (salts and metals) in those fractions.

\section{Activity 3: Quantum Modeling}

The most advanced technology for the control of mercury emissions from coal-fired power plants is the injection of powdered activated carbon into the flue gas stream ahead of the particulate control device. To minimize the carbon-to-mercury ratio, both fast kinetics and high capacity are required. Extensive parametric experimentation has elucidated the interaction of mercury with flue gas components on activated carbon, and spectroscopic examination of the sulfur and chlorine forms present before and after breakthrough has led to an improved model for explaining the kinetic and capacity results. The model describes a zigzag carbene site on the carbon edge that can function as a Lewis acid oxidation site for mercury that is activated by acidic gas components. The same Lewis acid site reacts with both the oxidized mercury and with the acidic flue gas components in competing reactions to form organochlorine, sulfinate, and sulfate ester moieties on the carbon edge. Owing to the difficulty of experimental measurements on carbon and the complexity of the reactions, details of reaction rates and thermodynamic stabilities have yet to be determined. Determination of the energy minima that determines thermodynamic and kinetic constants for zigzag carbene and armchair benzyne structures with $\mathrm{Hg}(\mathrm{II})$ and $\mathrm{HCl}$ and for the corresponding carbenium ions with $\mathrm{Hg}(0)$ and halide ions would contribute to the understanding of mercury interactions on carbon.

Density functional theory (DFT) calculations employing the MPW3LYP functional have been performed to further elucidate a recently developed mechanistic model for mercury speciation in coal combustion systems and interactions on activated carbon. The calculations were carried out using the $6-311+\mathrm{G}^{* *}$ basis set for the organic moiety and the Stuttgart 1997 effective core potential basis set for the mercury atom. A prior assessment of some theoretical electronic structure methods led to the conclusion that the MPW3LYP/6-311+G** level is computationally less expensive yet accurate enough to be used in modeling larger coal-mimetic molecules. Energy minima have been calculated for important reactants, intermediates and product species on the proposed scheme. Harmonic vibrational frequencies were also computed to verify that the stationary structures were local minima and to obtain zero-point corrected energies. Reaction energies, enthalpies, free energies, and binding energies of $\mathrm{Hg}^{0}$ to the prototype molecules were derived from the data obtained in these calculations. Bimolecular rate constants for the various elementary steps in the mechanism have been estimated using the hardsphere collision theory approximation, and the results seem to indicate that extremely fast kinetics could be involved in these surface reactions.

\section{Activity 4: High-Potassium Carbon Production with Biomass-Coal Blending}

The primary objective for this activity was to test the ability for carbons made of highpotassium biomass blended with coal to produce carbon for use in coal-fired flue gases for mercury control. Selection of the materials to be utilized has identified lignite coal from the 
Center Mine in North Dakota and sunflower hulls for the biomass material to be carbonized. It is hypothesized that the alkali and alkaline-earth elements present in the sunflower hulls as well as the lignite coal may improve mercury capture in the high-sulfur environment of bituminous coalfired flue gases that have shown to require high levels of carbon injection ( 5 to $7 \mathrm{lb} / \mathrm{Macf}$ ) to achieve mercury removal. It is known that $\mathrm{SO}_{2}$ (and possibly $\mathrm{SO}_{3}$ ) present in bituminous coalfired flue gases compete for active carbon sorbent sites. This subtask will evaluate the ability of the alkali and alkaline-earth elements present in the biomass-carbon product to react with and remove $\mathrm{SO}_{2}$ and $\mathrm{SO}_{3}$, thereby leaving the carbon sites available for mercury capture. The activated carbon produced from the blend of sunflower hulls and lignite coal had a very high surface area. However, the ability to remove mercury from a bituminous coal's derived flue gas was low. Removals of only 15\% were attained injecting at rates of $6 \mathrm{lb} /$ Macf of activated carbon upstream of an electrostatic precipitator. 


\section{BASE SUBTASK 2.10 ADVANCED FINE PARTICULATE CHARACTERIZATION}

\section{INTRODUCTION}

This task consisted of four activities that include the following.

\section{Activity 1: Further Development of Analytical Techniques for $\mathbf{P M}_{10}$ and $\mathbf{P M}_{2.5}$ Characterization and Source Apportionment and Management}

The characterization and control of emissions from combustion sources is of significant importance in improving local and regional air quality. Such emissions include fine particulate matter, organic carbon compounds, and $\mathrm{NO}_{\mathrm{x}}$ and $\mathrm{SO}_{2}$ gases, along with mercury and other toxic metals.

Particles less than $10 \mu \mathrm{m}\left(\mathrm{PM}_{10}\right)$, and in particular less than $2.5 \mu \mathrm{m}\left(\mathrm{PM}_{2.5}\right)$, are of increasing concern. Their contribution to urban smog and regional background pollution is well known. Because of this, past studies using scanning electron microscopy (SEM) techniques developed at the Energy \& Environmental Research Center (EERC) were used to provide timeresolved size and composition information for over a quarter million particles. The time-resolved analyses provided valuable information for source apportionment. However, many of the particles are too small to be positively identified by the particle chemistries provided by SEM systems. Incorporating other analytical tools such as $\mathrm{x}$-ray diffraction (XRD) to the characterization of ambient air particulates to identify, and possibly quantify, crystalline phases from the same sample sets, along with further classification of SEM data already collected, will provide for more exact apportionment of the aerosols and larger particulates captured. The ability to rapidly and accurately characterize airborne particulates will have use in many areas from forensic science to national security.

\section{Activity 2: Organic Carbonaceous Particulate and Metal Speciation for Source Apportionment Studies}

The methods for characterization of carbonaceous particulate matter (PM) are either too complex (e.g., determining hundreds of compounds) or oversimplified, determining only organic and elemental carbon $[\mathrm{OC}, \mathrm{EC}])$. Even though detailed characterization is available, the methods used are suitable mainly for nonpolar and slightly polar species. Consequently, the information on the overall distribution of different polarity organics is not available. The significance of organic PM differentiation based on the polarity is in linking the PM to primary (nonpolars) and secondary (polars) aerosol sources.

Thus we have developed a method differentiating organic PM into four different polarity fractions. We have shown that even for diesel exhaust PM, which is considered to be nonpolar, the largest portion of OC was extracted in the midpolarity fraction. All types of OC (polar, midpolarity, and nonpolar) were evenly distributed over both wood smoke and urban PM samples. The results on the distribution of polar and midpolarity organics were supported by near-edge $\mathrm{x}$-ray absorption fine structure (NEXAFS) spectroscopy, which allows for 
differentiation of different carbon bonds. Our data confirmed our initial hypothesis that polar species represent significant portion of PM from different sources. In most studies, they are neglected and, therefore, need further attention in PM research.

\section{Activity 3: Quantum Mechanical Modeling of Mercury Speciation in Coal Combustion Systems and Interactions on Activated Carbon}

Mercury speciation in coal combustion systems is an important area of research, especially as it relates to the control of mercury emissions which is a major concern in coal-fired power industries. The injection of powdered activated carbon (AC) into the flue gas stream of coal-fired power plants is currently one of the technologies for controlling mercury emissions. However, the mechanisms of mercury interactions with flue gas components on AC surfaces are complex and rarely understood; consequently, there is considerable research interest on this subject. This activity was focused on using a theoretical approach to evaluate the $\mathrm{Hg}$ interactions with carbon by the proposed zigzag and armchair carbon graphene-edge structures. Since the computational accessibility of most modern quantum chemical electronic structure methods is limited to small or moderately sized molecules, it was necessary to perform an assessment of existing theoretical methods with the aim to find a suitable theory level to perform computations on the larger coalmimetic AC prototype molecules. With an appropriate theory level found, the remaining goals of the project were twofold: to determine energy minima on the potential energy surfaces (PESs) of the important structures and to compute quantitative estimates of the relative thermodynamic stabilities of the species, as well as reaction rates and rate constants.

\section{Activity 4: High-Potassium Carbon Production with Biomass-Coal Blending}

Pilot-scale studies have shown that high-sodium lignite chars and ACs have the ability to capture mercury present in coal combustion flue gases. The presence of halogens enhances mercury control. Many biomass materials contain significant levels of halogens and potassium. The goal of this activity was conducted to produce high-potassium carbons from biomass and coal blends that have the potential to improve mercury capture.

\section{ACTIVITY ACCOMPLISHMENTS}

\section{Activity 1: Further Development of Analytical Techniques for $\mathbf{P M}_{10}$ and $\mathbf{P M}_{2.5}$ Characterization and Source Appointment and Management}

\section{Introduction}

The goal of Activity 1 was to improve analytical methods and data interpretation by creating software to improve SEM morphology analyses and improving methods of automated small particle analysis.

The work conducted on improving analytical methods and data interpretation focused on improving SEM characterization and data reductions. 
A new procedure of SEM morphology analysis and new software presenting results of morphology analysis was developed. The new procedure improves automated morphology analysis and generates a better data format of results. The new software renders the SEM image, lists the results of point analysis in chemical compositions by either element or oxide weight percent, and labels locations of the points on the image.

The previous procedure for morphology analysis had three steps: 1) take a Polaroid picture of the interested area of a sample; 2) perform point analysis on interesting areas, label the points analyzed by hand, and print out each point analysis result; and 3) manually input the result of each point analysis to a spreadsheet. The new software greatly enhances our ability to interpret the SEM information quickly since it is now in an electronic file of image with typed labels and can be included directly into a report. For each image or set of images, one file is created that includes the chemical analysis of the selected labeled points or areas that can be combined in one file and printed on one page of paper.

\section{Results}

The morphological analysis procedure involves the following steps: 1) saving an image file of the sample instead of a Polaroid picture, 2) saving the location and results of point analysis in a single file, and 3) combining the image and point analyses into a single file. Step 2 has been implemented by writing a UNIX shell script program running on the computer system on the SEM. Step 3 has been implemented by developing a new program running on Microsoft Windows platform. The new software has the following functionalities: 1) importing and rendering images, 2) importing the point and area analysis file and extracting the location and chemical information of each point, 3) labeling the analyzed points on the image and listing the chemical composition of each point, 4) editing labels of points if necessary, 5) storing the image and analysis in a single file, 6) exporting analysis results to an Excel formatted file, and 7) printing the image and analysis data in a single page of paper.

Figure 1 is a snapshot of the morphology software as it appears on the screen of the computer system.

Another example of the new morphology software is shown in Figure 2 and Table 1. The software performs semiautomated analysis on PM particles as well as ash and other materials. The software automatically generates pictures that include numbered analysis locations and a table of chemical analysis for the numbered points. In addition, the system provides nearly pixelby-pixel chemical analysis.

This system is currently being utilized for analysis in the Natural Materials Analytical Research Laboratory (NMARL). An example output of a cross section of an ash material is shown below in Figure 2.

Particulate samples produced from a subbituminous coal from the Powder River Basin (PRB) were collected downstream of various control technologies installed on the EERC particulate test combustor and characterized by the EERC's automated SEM techniques. The 


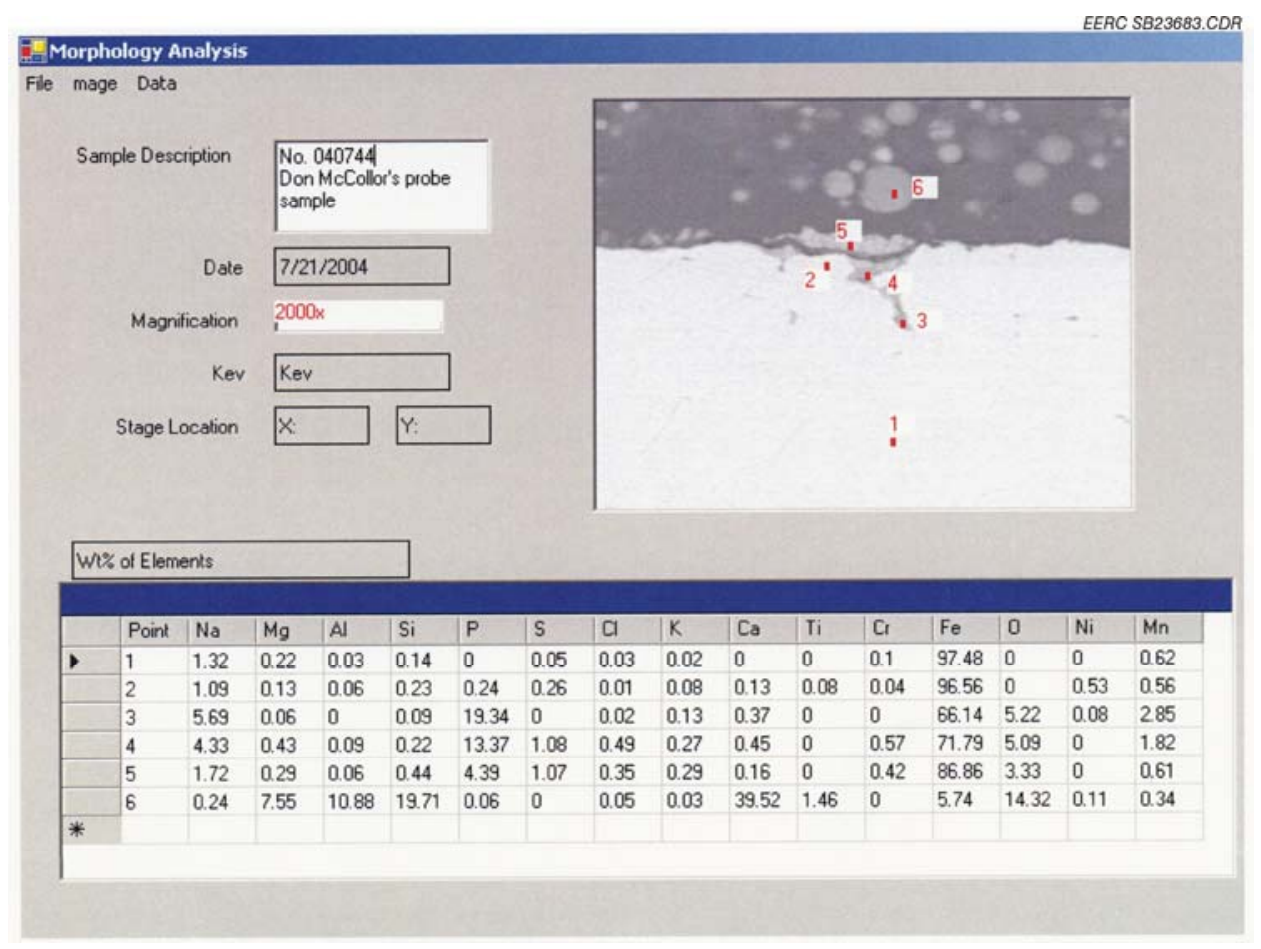

Figure 1. Snapshot of morphological analysis.

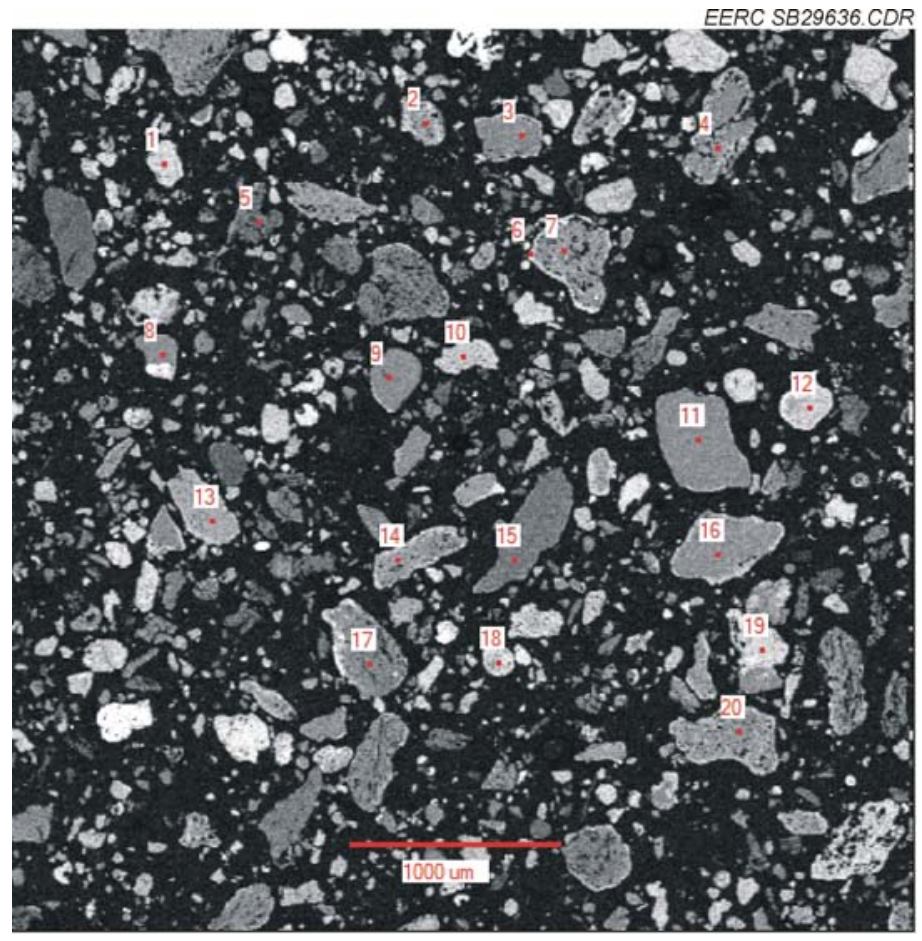

Figure 2. Backscattered electron image of an ash sample with numbered points analyzed. 
Table 1. Analysis of Point in Figure 2, Results Express as Elemental Weight Percent

\begin{tabular}{lccccccccccccc}
\hline Point & $\mathrm{Na}$ & $\mathrm{Mg}$ & $\mathrm{Al}$ & $\mathrm{Si}$ & $\mathrm{P}$ & $\mathrm{S}$ & $\mathrm{Cl}$ & $\mathrm{K}$ & $\mathrm{Ca}$ & $\mathrm{Ti}$ & $\mathrm{Cr}$ & $\mathrm{Fe}$ & $\mathrm{Ba}$ \\
\hline 1 & 0.0 & 0.0 & 0.0 & 0.0 & 0.0 & 16.8 & 1.0 & 0.0 & 82.2 & 0.0 & 0.0 & 0.0 & 0.0 \\
2 & 0.5 & 0.0 & 9.5 & 63.0 & 0.0 & 2.6 & 0.0 & 3.0 & 21.4 & 0.0 & 0.0 & 0.0 & 0.0 \\
3 & 0.0 & 0.0 & 0.0 & 100.0 & 0.0 & 0.0 & 0.0 & 0.0 & 0.0 & 0.0 & 0.0 & 0.0 & 0.0 \\
4 & 0.0 & 0.0 & 7.9 & 45.1 & 0.0 & 0.0 & 0.0 & 0.0 & 47.1 & 0.0 & 0.0 & 0.0 & 0.0 \\
5 & 0.0 & 0.0 & 40.4 & 59.6 & 0.0 & 0.0 & 0.0 & 0.0 & 0.0 & 0.0 & 0.0 & 0.0 & 0.0 \\
6 & 0.0 & 0.0 & 4.6 & 34.2 & 0.0 & 0.0 & 0.0 & 0.0 & 61.2 & 0.0 & 0.0 & 0.0 & 0.0 \\
7 & 0.0 & 1.1 & 21.7 & 48.3 & 0.0 & 0.0 & 0.0 & 4.6 & 24.3 & 0.0 & 0.0 & 0.0 & 0.0 \\
8 & 0.0 & 0.0 & 0.0 & 100.0 & 0.0 & 0.0 & 0.0 & 0.0 & 0.0 & 0.0 & 0.0 & 0.0 & 0.0 \\
9 & 0.0 & 0.0 & 0.0 & 100.0 & 0.0 & 0.0 & 0.0 & 0.0 & 0.0 & 0.0 & 0.0 & 0.0 & 0.0 \\
10 & 0.0 & 0.0 & 0.0 & 0.0 & 0.0 & 9.5 & 1.1 & 0.0 & 89.5 & 0.0 & 0.0 & 0.0 & 0.0 \\
11 & 0.0 & 0.0 & 0.0 & 100.0 & 0.0 & 0.0 & 0.0 & 0.0 & 0.0 & 0.0 & 0.0 & 0.0 & 0.0 \\
12 & 0.0 & 0.0 & 0.8 & 0.0 & 0.0 & 34.0 & 0.0 & 0.0 & 65.2 & 0.0 & 0.0 & 0.0 & 0.0 \\
13 & 0.0 & 0.0 & 30.0 & 44.5 & 0.0 & 1.8 & 0.0 & 0.0 & 23.7 & 0.0 & 0.0 & 0.0 & 0.0 \\
14 & 0.8 & 1.2 & 22.6 & 59.4 & 0.0 & 0.0 & 0.0 & 4.6 & 11.4 & 0.0 & 0.0 & 0.0 & 0.0 \\
15 & 0.0 & 0.0 & 36.1 & 64.0 & 0.0 & 0.0 & 0.0 & 0.0 & 0.0 & 0.0 & 0.0 & 0.0 & 0.0 \\
16 & 0.0 & 0.0 & 1.5 & 94.8 & 0.0 & 0.0 & 0.0 & 3.7 & 0.0 & 0.0 & 0.0 & 0.0 & 0.0 \\
17 & 0.0 & 0.0 & 2.8 & 97.2 & 0.0 & 0.0 & 0.0 & 0.0 & 0.0 & 0.0 & 0.0 & 0.0 & 0.0 \\
18 & 0.0 & 1.9 & 7.6 & 25.4 & 4.8 & 0.0 & 0.0 & 0.0 & 44.9 & 3.4 & 0.0 & 12.0 & 0.0 \\
19 & 0.0 & 0.0 & 0.0 & 0.0 & 0.0 & 22.2 & 0.0 & 0.0 & 77.8 & 0.0 & 0.0 & 0.0 & 0.0 \\
20 & 0.0 & 0.0 & 3.1 & 80.3 & 0.0 & 0.0 & 0.0 & 0.0 & 16.7 & 0.0 & 0.0 & 0.0 & 0.0 \\
\hline
\end{tabular}

characteristics of the PM emitted from various air pollution control device configurations including electrostatic precipitator (ESP) only, ESP/baghouse, baghouse only, spray dryer absorber spray dryer absorbers (SDA)/ESP, and SDA/fabric filter (FF) were examined. Samples have been characterized, and analyzed. As expected, the least amount of sample was collected downstream of the ESP/baghouse, followed by the SDA/FF, SDA/ESP, and ESP only. The primary component present in the SDA/ESP was calcium with minor amounts of sodium associated with phosphorus and sulfur species. The primary components found downstream of the SDA/FF were rich in calcium. The ESP/baghouse had very small amounts of calcium-rich particles. The ESP only had more particles, and in addition to the calcium sulfate-type particles, the sample contained some aluminosilicates.

Examples of the size analysis conducted for Absaloka coal combustion-derived particulate is illustrated in Figure 3. The results indicate the SDA/FF collects more of the fine particulate as compared to the ESP. Figure 4 shows the results obtained for Caballo coal combustion-derived particulate matter showing the results of particulate-size distributions. The PM with the largest size distribution is the SDA/ESP, followed by the ESP only, with the SDA/FF being the finest.

\section{Conclusions}

A software application for the WinEDS has been developed for morphology analysis. With this new software, semiautomated point analysis and reporting can be performed. The analysis report combines the SEM images with the point analysis into a single document for printing or editing by Microsoft Word. This new morphology software can also export Excel files. 


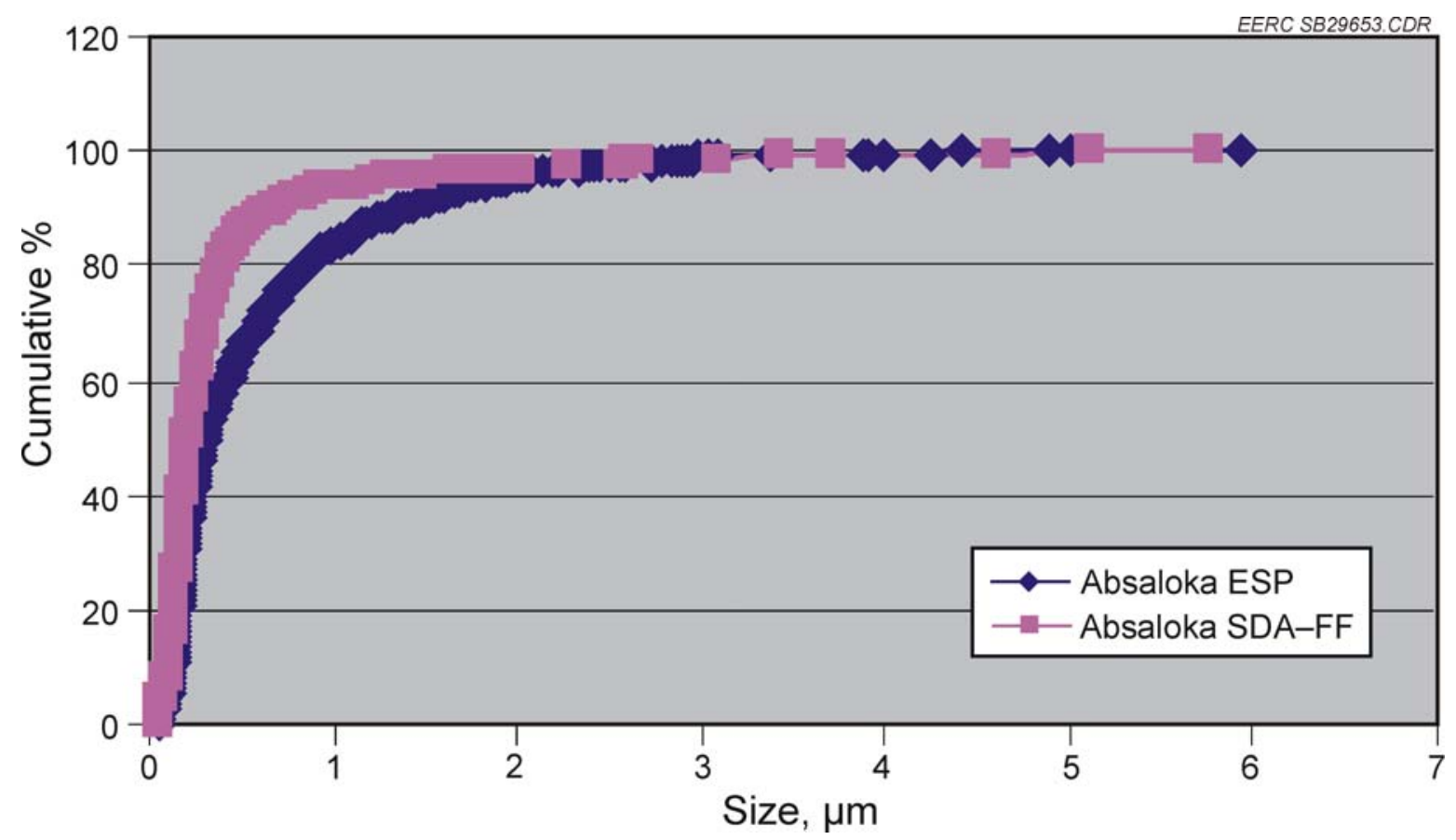

Figure 3. Particle-size distribution of fine particulate collected downstream of an ESP and $\mathrm{SDA} / \mathrm{FF}$ for Absaloka coal.

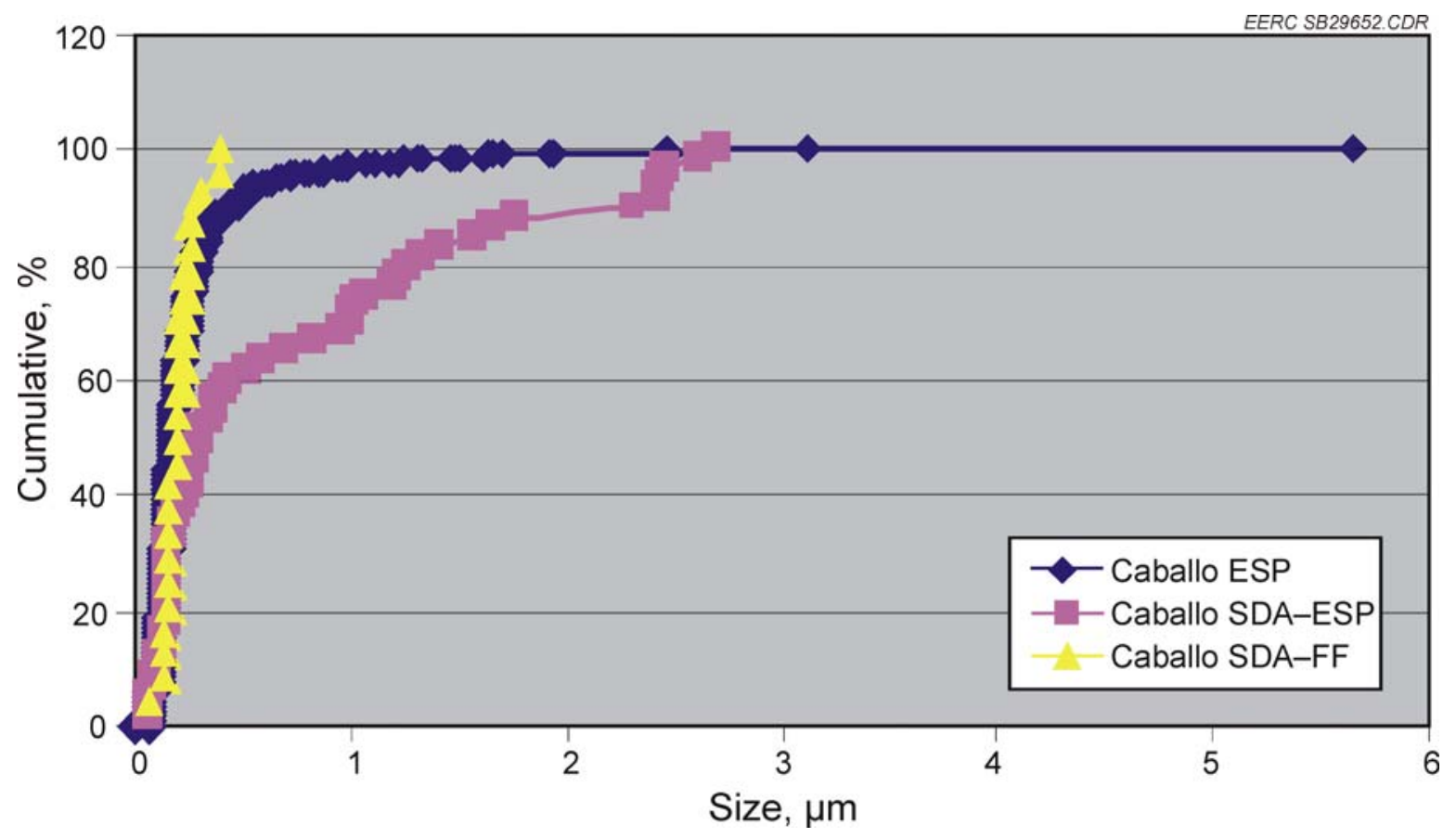

Figure 4. Particle-size distribution of fine particulate collected downstream of an ESP, SDA/ESP, and SDA/FF for Caballo coal combustion $\mathrm{PM}_{2.5}$ testing. 
Particulate samples produced from a subbituminous coal from the PRB were collected downstream of various control technologies and characterized by the EERC's automated SEM techniques. The primary component present in the SDA/ESP was calcium with minor amounts of sodium associated with phosphorus and sulfur species. The primary components found downstream of the SDA/FF were rich in calcium. The ESP/baghouse had very small amounts of calcium-rich particles. The ESP only had more particles, and in addition to the calcium sulfatetype particles, the sample contained some alumninosilicates.

\section{Activity 2: Organic Carbonaceous Particulate and Metal Speciation for Source Apportionment Studies}

\section{Introduction}

Complete chemical characterization of PM is needed to evaluate its toxicological, epidemiological impact, as well as the chemistry of atmospheric processes. While inorganics (e.g., metals, salts) are well characterized, the complexity of organic PM causes only partial information to be available for carbonaceous PM. Using a thermal optical transmittance analyzer, the total carbon is typically differentiated into three forms: organic, elemental and carbonate carbon. With regard to hundreds of different organics in PM, the determination of OC as a single number seems to be oversimplified. Another approach involves detailed analysis of extractable organics using organic solvent extraction and gas chromatography/mass spectroscopy (GC/MS) analysis. However, such determination is time- and cost-intensive, and moreover, is limited to nonpolar or slightly polar OC. Several recent toxicological studies stressed the importance of polar OC. ${ }^{1,2}$ However, because of technical difficulties, only targeted analysis on selected species is performed. The differentiation of carbonaceous species on polar and nonpolar is important from the formation point of view. While nonpolar PM is related to primary emissions, polar organics is related to secondary emissions.

Previous studies evaluating OC extraction recoveries from PM showed that no single solvent is efficient enough. ${ }^{3}$ Thus a variety of solvents, and their mixtures, has been used. ${ }^{3-5}$ In our previous work we have shown that hot pressurized water had higher recoveries of PM than polar solvents such as methanol. ${ }^{6}$ The advantage of hot pressurized water over organic solvents is that it can extract, at lower temperatures, polar, and, at higher temperatures, nonpolar species. Consequently, hot pressurized water can selectively extract various compounds at different temperatures, such as phenols, monoaromatics, and polycyclic aromatic hydrocarbons from petroleum sludge. ${ }^{7}$

Thus temperature is one of the parameters defining optimal conditions of hot pressurized water extraction. An additional parameter which may be evaluated is the flow rate at which extraction is performed. Increasing flow rate may enhance extraction, depending on whether the hot pressurized water extraction is controlled by near equilibrium partitioning (thermodynamic model) or the rate of analyte desorption (kinetic model). ${ }^{8}$

NEXAFS spectroscopy has been previously shown to be a good technique for the molecular speciation of carbonaceous PM, with the potential of identifying markers. ${ }^{9}$ In NEXAFS, the carbon K-shell (1s) spectra allows distinguishing $\mathrm{C}=\mathrm{C}, \mathrm{C}=\mathrm{O}, \mathrm{C}-\mathrm{OH}$, and $\mathrm{COOH}$ bonds based on the resonance energies of $285,286,287$, and $288 \mathrm{eV}$, respectively. ${ }^{9}$ 


\section{Experimental Results and Discussion}

\section{Material}

Three different PM samples were selected for the study: diesel exhaust PM from an industrial forklift (standard reference material [SRM] 2975) and urban air PM (SRM 1648) both from the National Institute of Standards and Technology (NIST) and wood smoke PM obtained from chimney scrapings after oak combustion. ${ }^{10}$ Hot pressurized water extractions were performed on 50-mg portions of PM samples.

\section{Extraction}

Hot pressurized water fractionation was performed using an extraction apparatus and a procedure previously described in detail. ${ }^{11}$ In brief, extractions were performed at flow rates of 0.5 and $1 \mathrm{~mL} / \mathrm{min}$ with water which was previously purged with nitrogen. Extractions were carried out in a 3.47-mL supercritical fluid extraction cell (9.4-mm i.d., 50-mm long, Keystone Scientific, Bellefonte, PA, USA) equipped with $0.5-\mu \mathrm{m}$ frits.

Hot pressurized water is known to be suitable for extraction of polar and mildly polar analytes. However, nonpolar analytes such as alkanes may be difficult to extract. ${ }^{7}$ Thus the evaluation of extraction efficiency involved three different extraction experiments (Table 2).

In each case, the aim was to obtain three/four different polarity fractions. The polar fractions and midpolarity fractions were always extracted with pressurized water at $25^{\circ} \mathrm{C}$ and $50^{\circ}-150^{\circ} \mathrm{C}$, respectively. At higher temperatures, some analytes may not be extracted; thus we compared the efficiency of hot pressurized water, steam, and organic solvent extraction (Methods B and C). Determination of OC in the residue after extraction with methylene chloride seemed to give incorrect output, possibly due to the residue of organic solvent in the PM. To determine $\mathrm{OC}$ and $\mathrm{EC}$ in the residue after the extraction with water and methylene chloride, we inverted the extraction process, starting with methylene chloride on a Soxhlet apparatus, followed by hot pressurized water extraction (Method B). Extractions with pressurized water were performed at pressures (5-100 bar) increasing with temperature sufficient to maintain water in the liquid state. Only extraction at $250^{\circ} \mathrm{C}$ with steam was carried out at a lower pressure of 5 bar. Each temperature was held constant for $15 \mathrm{~min}$, at which time, the collection vial was replaced, and the system heated to the next higher temperature (requiring 30-90 s). The

Table 2. Experimental Conditions Employed for Extraction of Carbonaceous PM

\begin{tabular}{|c|c|c|c|}
\hline \multirow[b]{2}{*}{ Extraction Method } & \multicolumn{3}{|c|}{ Fractions Extracted } \\
\hline & 1 & 2 & 3 \\
\hline A & Water $25^{\circ} \mathrm{C}$ & Water $50^{\circ}-150^{\circ} \mathrm{C}$ & \\
\hline B & Methylene chloride & Water $25^{\circ} \mathrm{C}$ & Water $50^{\circ}-150^{\circ} \mathrm{C}$ \\
\hline $\mathrm{C}$ & Water $25^{\circ} \mathrm{C}$ & Water $50^{\circ}-150^{\circ} \mathrm{C}$ & $\begin{array}{c}\text { Water } 200^{\circ}-250^{\circ} \mathrm{C} \text { and } \\
\text { Steam }^{\mathrm{a}} 250^{\circ} \mathrm{C}\end{array}$ \\
\hline
\end{tabular}


methylene chloride Soxhlet extraction was performed on a sample air-dried overnight (18 h). After each extraction, the system was washed with pressurized water and steam. Between samples, the system was also washed with a sequence of acetone, methylene chloride, and acetone ( $5 \mathrm{~mL}$ each).

\section{Carbonaceous analysis}

Determination of total organic carbon (TOC) in aqueous extracts was performed by MVTL Laboratories Inc. (New Ulm, Minnesota) using Standard Method 5310C. The OC/EC determinations were performed by Sunset Laboratories (Tigard, Oregon) using a thermal optical transmittance analyzer, Method NIOSH 5040.

\section{NEXAFS}

NEXAFS spectroscopic determinations were performed by Dr. A. Braun (Department of Chemical and Materials Engineering, University of Kentucky, Lexington) at the ultrahigh vacuum beamline 9.3.2., at the Advanced Light Source in Berkeley National Laboratory, Berkeley, California. The detection mode was the sample current. The energy resolution was $0.05 \mathrm{eV}$. Spectra were collected at x-ray energies from 270 to $300 \mathrm{eV}$ in $0.1-\mathrm{eV}$ increments. All spectra were divided by the incident beam intensity.

\section{Determination of Inorganics}

The cation analyses were performed using a Dionex Ion chromatograph equipped with conductivity detector (Sunnyvalle, California). The samples were filtered though Gelman 0.2- $\mu \mathrm{m}$ IC Acrodisc syringe filters (Ann Arbor, Michigan) prior to injection using a $100-\mu \mathrm{L}$ loop. A Dionex IonPac ${ }^{\circledR}$ CG5A/CS5A guard and analytical columns were used for the separation. The mobile phase consisted of $3 \mathrm{mM}$ pyridine-2,6-dicarboxylic acid, $4.2 \mathrm{mM} \mathrm{LiOH}$ monohydrate, $3 \mathrm{mM}$ sodium oxalate, sodium sulfate. ${ }^{12}$ The cations were detected using UV-visible detector at $535 \mathrm{~nm}$ after a postcolumn derivatization with two different derivatization reagents 4-2 (2-pyridylazo) resorcinol (PAR) and 2-[(5-bromo-2-pyridyl)-azo]-5-diethyl-aminophenol (5-Br-PADAP). ${ }^{12}$

The anion analysis was performed on a Dionex DX-80 anion chromatographic analyzer equipped with a $10-\mu \mathrm{L}$ sample loop, a membrane eluent suppression system, and AG14/AS14A guard and separation columns. The mobile phase consisted of $3.5 \mathrm{mM}$ sodium carbonate and $1.0 \mathrm{mM}$ sodium bicarbonate. Analyses were performed at flow rate of $1.2 \mathrm{~mL} / \mathrm{min}$.

\section{Statistical Analysis}

Statistical comparisons were performed using a two-way analysis of variance for $p<0.05$ using Prism software (GraphPad). Results were expressed as the mean \pm one standard deviation.

In the framework of this project, the following tasks were completed:

- Determination of the hot pressurized water extraction mechanism from various PM samples. 
- Evaluation of $\mathrm{OC}$ fractionation to different polarity fractions using hot pressurized water and methylene chloride.

- NEXAFS characterization of different polarity fractions.

- Determination of inorganic anions (salts) in hot pressurized water extracts.

- The method development of ion chromatographic analysis of metals in aqueous extracts.

- Presentation of results on the annual meeting of the American Association for Aerosol Research (AAAR) in Austin, Texas, October 17-21, 2005.

\section{Mechanism of Hot Pressurized Water Extraction}

Previously, we had shown that by changing the extraction flow rate, we can determine whether the extraction is controlled thermodynamically (based on the partitioning) or kinetically (based on the rate of desorption). In the case of thermodynamic equilibrium, the partitioning of analyte is not affected by a change in the flow rate. Thus at higher flow rates, faster extraction occurs. In contrast, if the extraction is controlled kinetically, the desorption is the limiting step, and a higher flow rate will not hasten extraction.

We have compared extraction at flow rates of 0.5 and $1 \mathrm{~mL} / \mathrm{min}$ (Figure 5). We did not observe an increase in the extraction rate when increasing the flow rate for all the PM samples tested. For wood smoke PM, there was a decrease in extraction efficiency, but further evaluation would be needed to confirmed statistical significance. In overall, hot pressurized water extraction of PM appears to be controlled by the desorption step; thus an increase in the extraction flow rates will not enhance extraction.

\section{Selective Extraction of Different Polarity Carbonaceous PM}

Hot pressurized water is especially useful for extraction of polar components. Wood smoke PM is a polar matrix; thus as expected, the recoveries with hot pressurized water were higher than any with other organic solvents (Figure 6 top). Diesel exhaust PM is considered to be a nonpolar matrix; thus lower recoveries were expected. Interestingly, the only solvent achieving the same recoveries for diesel exhaust PM as hot pressurized water was methanol, which is polar. These results confirm previously reported toxicological reports that a significant portion of diesel exhaust PM is polar. ${ }^{6}$

Further evaluation of extraction efficiency of OC was performed on three different PM samples with OC content of 7\% (wt of PM) for diesel exhaust PM, 10\% for urban PM, and $58 \%$ for wood smoke PM. As mentioned above, hot pressurized water is suitable for extraction of polar and midpolarity organics. However, nonpolar species such as alkanes may not be extracted. Thus we have extracted polar and midpolarity species using hot pressurized water and compared extraction efficiency of nonpolar organics with methylene chloride and with 

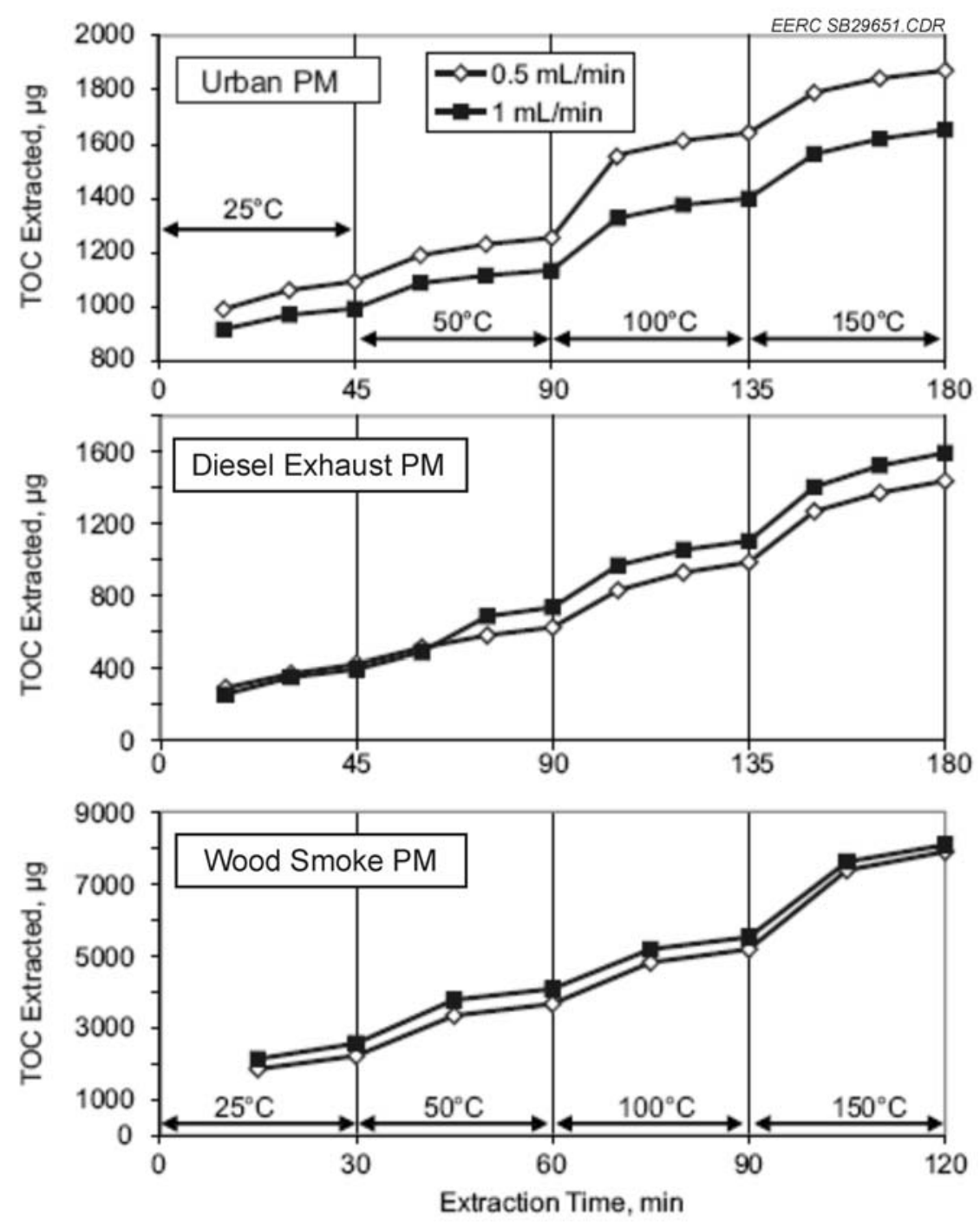

Figure 5. The effect of flow rate on the OC recoveries extracted from 50-mg portions of PM samples using sequential hot pressurized water extraction $\left(25^{\circ}-150^{\circ} \mathrm{C}\right)$.

higher-temperature $\left(>200^{\circ} \mathrm{C}\right)$ pressurized water and steam. The comparison on the basis of $\mathrm{EC} / \mathrm{OC}$ ratio in the residue after the extraction is shown in Figure 7. Higher recoveries of OC obtained by hot pressurized water and steam (Method $C$ ) may be due to harsher matrix disrupting conditions. No statistically different data $(p>0.05)$ were obtained for EC/OC ratio of residues extracted with hot pressurized water without and with methylene chloride (Methods A and B). Since we could not evaluate the effect of methylene chloride based on the OC and EC analysis of residue, we have compared $\mathrm{OC}$ recoveries in aqueous extracts obtained with hot pressurized 

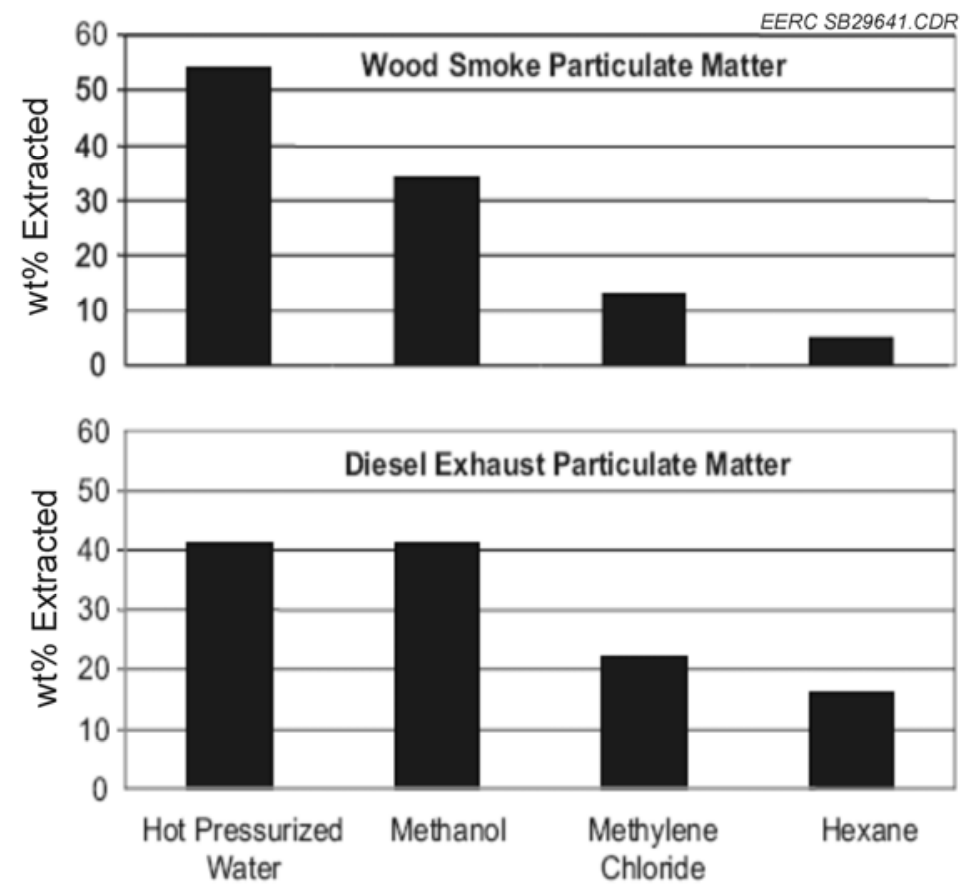

Figure 6. Comparison of mass extracted from wood smoke and diesel exhaust PM using different solvents.

water directly and after the extraction with methylene chloride (Figure 8). The significant amounts of OC in aqueous extracts after methylene chloride extraction (Method B) suggest that methylene chloride is not efficient in extracting polar and midpolarity organics.

Bioavailability of organics is sometimes related to the extractable PM. Depending on the sample origin, $35 \%-50 \%$ of OC was extractable when using hot pressurized water/steam (Figure 9). Based on the previous results on polar organics and current results on extraction of nonpolars, hot pressurized water seems to be a suitable tool for characterization of extractable OC. ${ }^{6}$ In this work, using pressurized water at different water temperatures, $\mathrm{OC}$ was differentiated to different polarity fractions (Figure 10). As expected, only small portion of diesel exhaust OC corresponded to polar species extracted at $25^{\circ} \mathrm{C}$. However, a significant portion of all $\mathrm{PM}$ samples including diesel exhaust was found in the midpolarity fraction (extracted at $50^{\circ}-150^{\circ} \mathrm{C}$ ). Nonpolar species (extracted at $200^{\circ}-250^{\circ} \mathrm{C}$ ) were of comparable abundance and midpolarity organics. As expected, polar species were extracted from wood smoke PM but were also strongly represented in urban PM.

\section{NEXAFS Characterization of Polar and Mid-Polarity Organics}

$\mathrm{C}(1 \mathrm{~s})$ NEXAFs has been previously shown to be suitable for characterization of aqueous PM extracts. This is because water does not contain carbon atoms and, therefore, does not create an undesirable background signature. ${ }^{9}$ Figure 11 shows that NEXAFS distinguishes major functional groups $\mathrm{C}=\mathrm{C}, \mathrm{C}=\mathrm{O}, \mathrm{C}-\mathrm{OH}$, and $\mathrm{COOH}$, which may be related to the polarity of those 

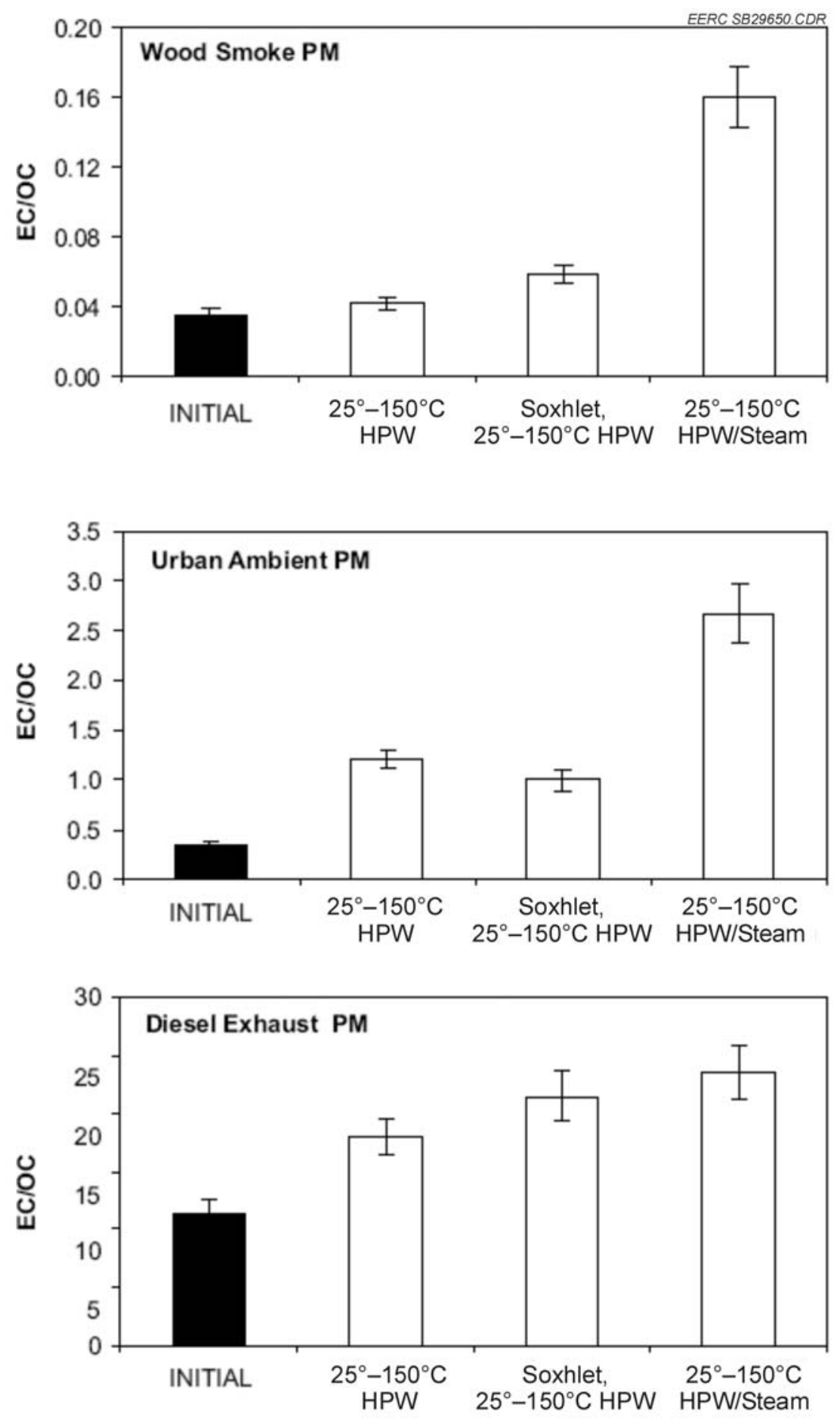

Figure 7. Comparison of $\mathrm{OC}$ extraction efficiency based on $\mathrm{EC} / \mathrm{OC}$ ratio from different types of PM using hot pressurized water (HPW). Polars and midpolarity were extracted at lower temperatures $\left(25^{\circ}-150^{\circ} \mathrm{C}\right)$, nonpolars at high temperatures $\mathrm{HPW} /$ steam $\left(200^{\circ}-250^{\circ} \mathrm{C}\right)$ or with methylene chloride using Soxhlet apparatus. 


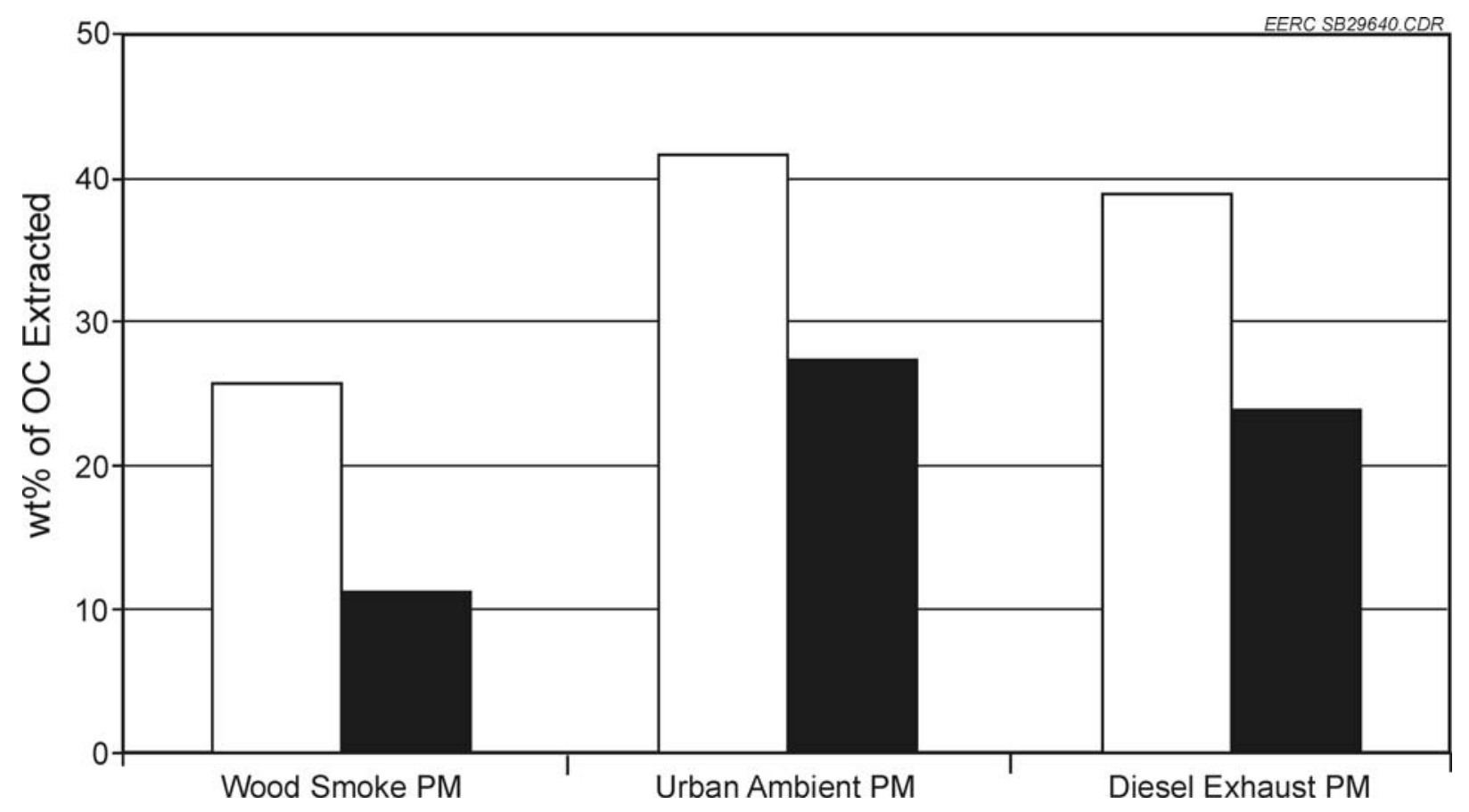

Figure 8. Polar and midpolarity OC extracted with $\mathrm{HPW}\left(25^{\circ}-150^{\circ} \mathrm{C}\right)$ directly and after the Soxhlet extraction with methylene chloride.

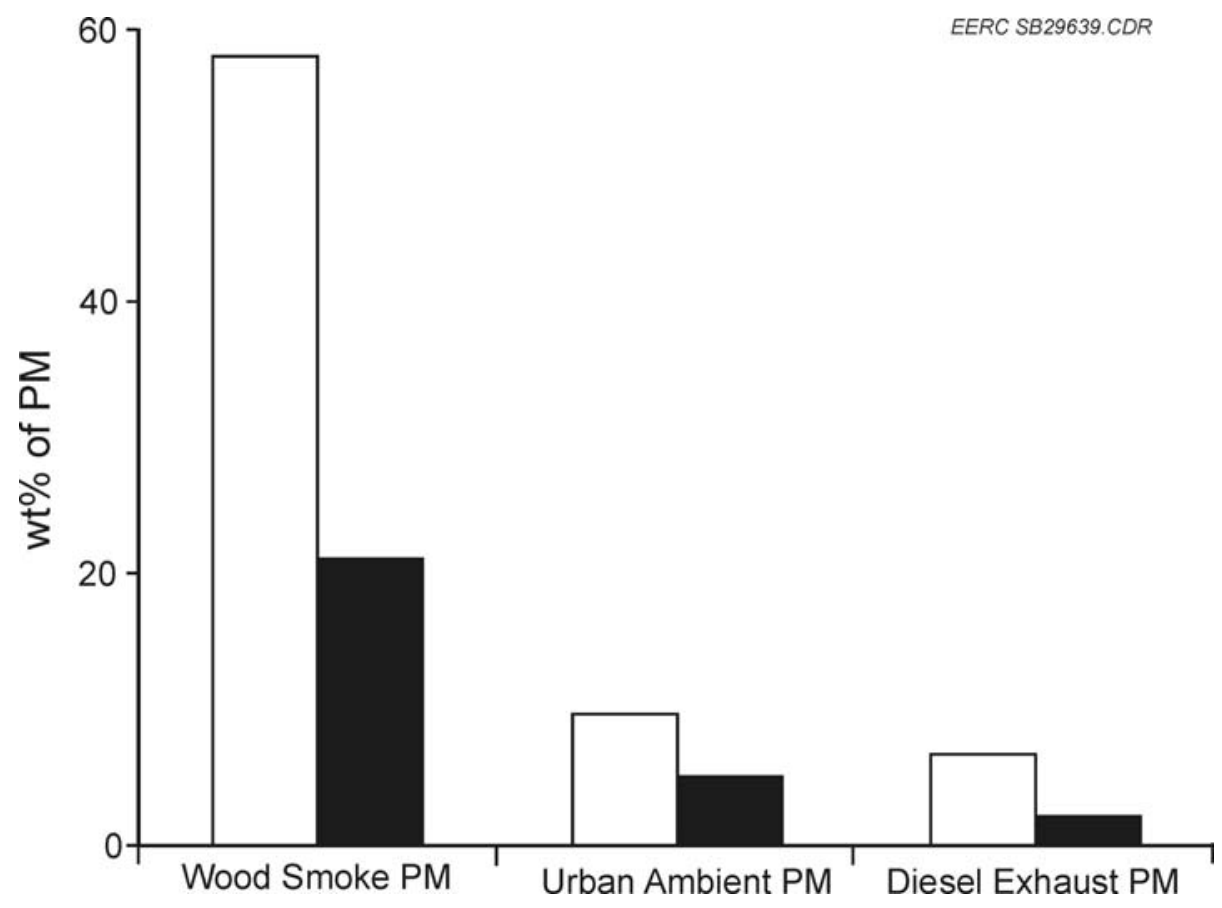

Figure 9. The OC (wt $\%$ ) content in PM samples (white bars) and OC wt $\%$ of extracted with HPW/steam (black bars). 


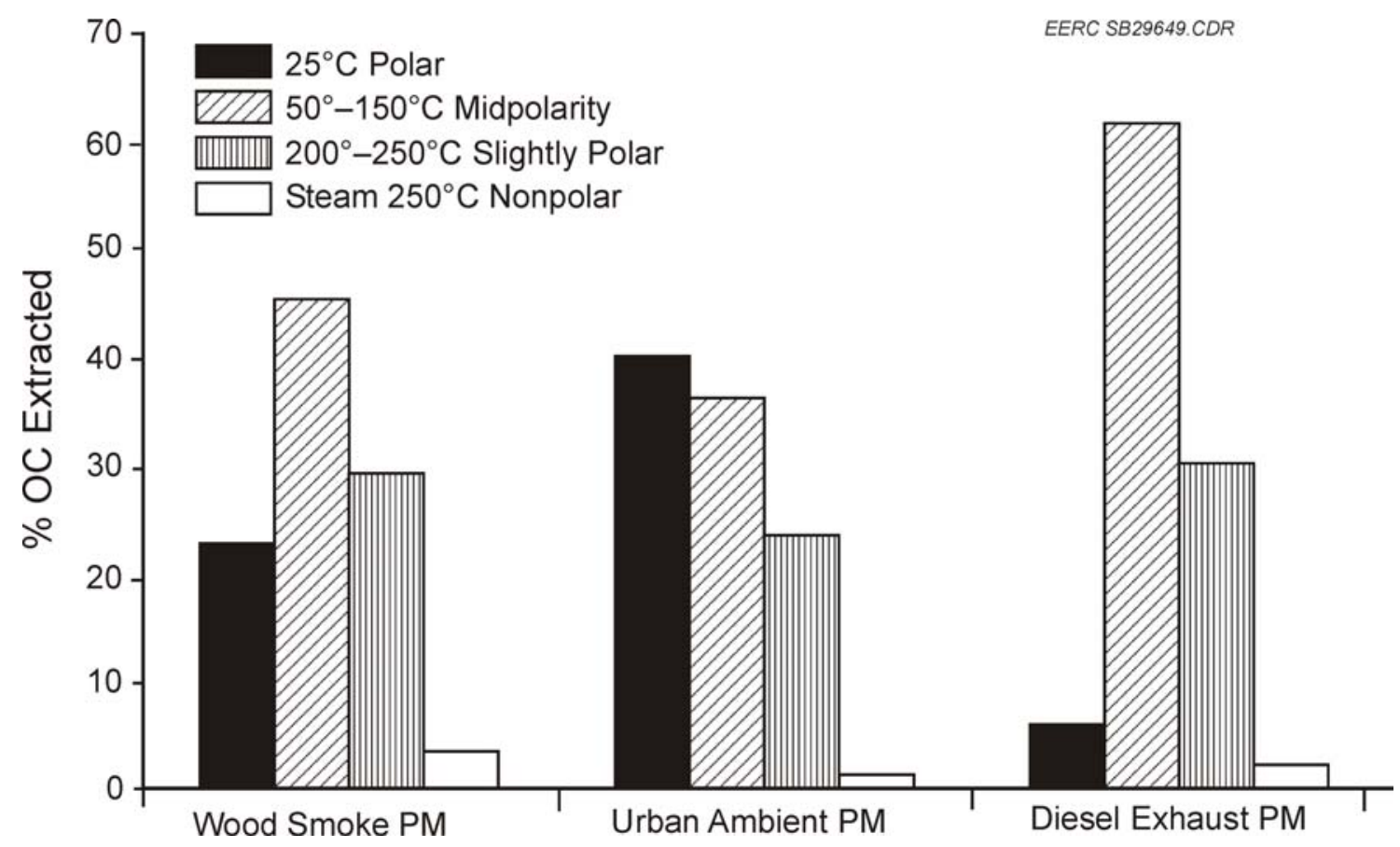

Figure 10. Distribution of different polarity OC determined using HPW extraction in PM samples of different origin.

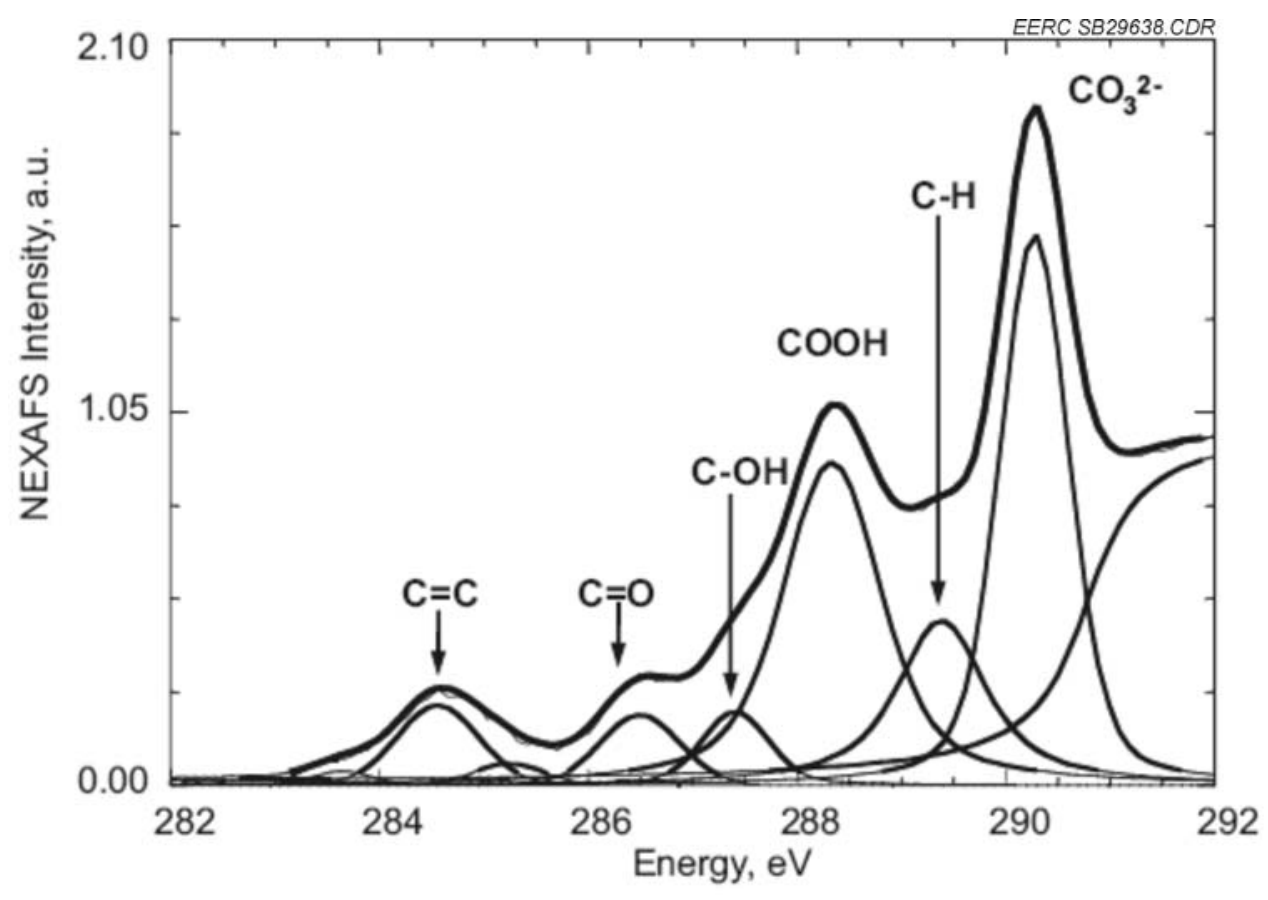

Figure 11. NEXAFS spectra differentiation of different carbon functional groups based on resonance energy. ${ }^{9}$ 
organic compounds. NEXAFS spectra of unextracted PM samples are complex and difficult to interpret (Figure 12). Strong bands at 287-288 eV corresponding to carbon-oxygen bonds typical for polar species (Figure 12) of urban and wood smoke PM may be related to polar organics found in first two temperature fractions (Figure 10). Nonpolar aromatic organics may be linked to $\mathrm{C}=\mathrm{C}$ bond found in all $\mathrm{PM}$ samples. However, this bond is typically related to graphitic carbon.

NEXAFS spectra were measured to obtain a direct relationship between the polarity of extracted organics and the chemical composition of polar and midpolarity fractions (Figure 12). We did not attempt to characterize nonpolar fractions, as they are well characterized by other techniques such as GC/MS. ${ }^{13}$ In addition, higher-temperature water is suitable for determination of the overall content of OC. However, at those temperatures, some hydrolysis may occur, and thus further chemical characterization may be misleading.

High OC recoveries in polar and midpolarity fractions of wood smoke PM can be related to polar organics such as methoxy phenols (syringols and guaiacols) and combustion products of cellulose - sugar anhydrides. ${ }^{6,14}$ The strong carboxylate and carbonyl/alcoholic bands in NEXAFS spectra of the $25^{\circ} \mathrm{C}$ fraction (Figure 12) correspond to our earlier GC/MS data showing high recoveries of carboxylic acids and methoxyphenols. ${ }^{6}$ The ratio of carbon-oxygen (polar) bonds versus $\mathrm{C}=\mathrm{C}$ (nonpolar) decreased with increasing temperature $\left(50^{\circ}-150^{\circ} \mathrm{C}\right.$ ) (Figure 12); still a significant portion of those polar organics was extracted in the midpolarity fraction when compared to the polar (Figure 10). ${ }^{14}$

Diesel exhaust PM NEXAFS showed an abundant peak for carboxylic acids in the $25^{\circ} \mathrm{C}$ fraction (Figure 12). Resonance bands of 287, $289 \mathrm{eV}$ suggest the occurrence of carboxylated and hydroxylated species also in midpolarity fractions. NEXAFS shows that an additional large portion of carboxylated and hydroxylated organics was extracted at $50^{\circ}-100^{\circ} \mathrm{C}$. This corresponds to the mass distribution of polar and midpolarity organics based on the HPW extraction (Figure 10), as well as previous reports on the occurrence of dicarboxylic acids in diesel exhaust particulate matter. ${ }^{15}$

NEXAFS of urban PM seems to be more complex than other samples. Interestingly, only a small band at $289 \mathrm{eV}$ corresponded to carboxylates. The majority of polar fractions seemed to be due to $\mathrm{C}=\mathrm{O}$ and $\mathrm{C}-\mathrm{OH}$ groups. Although a significant portion of polar organics was extracted at ambient temperatures, no corresponding resonance bands were found in NEXAFS spectra.

\section{Determination of Inorganics}

To further characterize the aqueous extracts, anion analyses were performed of all fractions obtained. The majority of inorganics was found in a fraction extracted at $25^{\circ} \mathrm{C}$. In contrast to urban PM, both wood smoke and diesel exhaust PM are carbonaceous matrices with a small amount of sulfate. In urban PM, a significant portion of different salts was found (Table 3). Sulfate was found also in higher-temperature fractions (Table 4). The higher recoveries of sulfate at $100^{\circ} \mathrm{C}$ corresponded to increased concentrations of iron and nickel at this temperature, as shown in our previous work. ${ }^{16}$ 

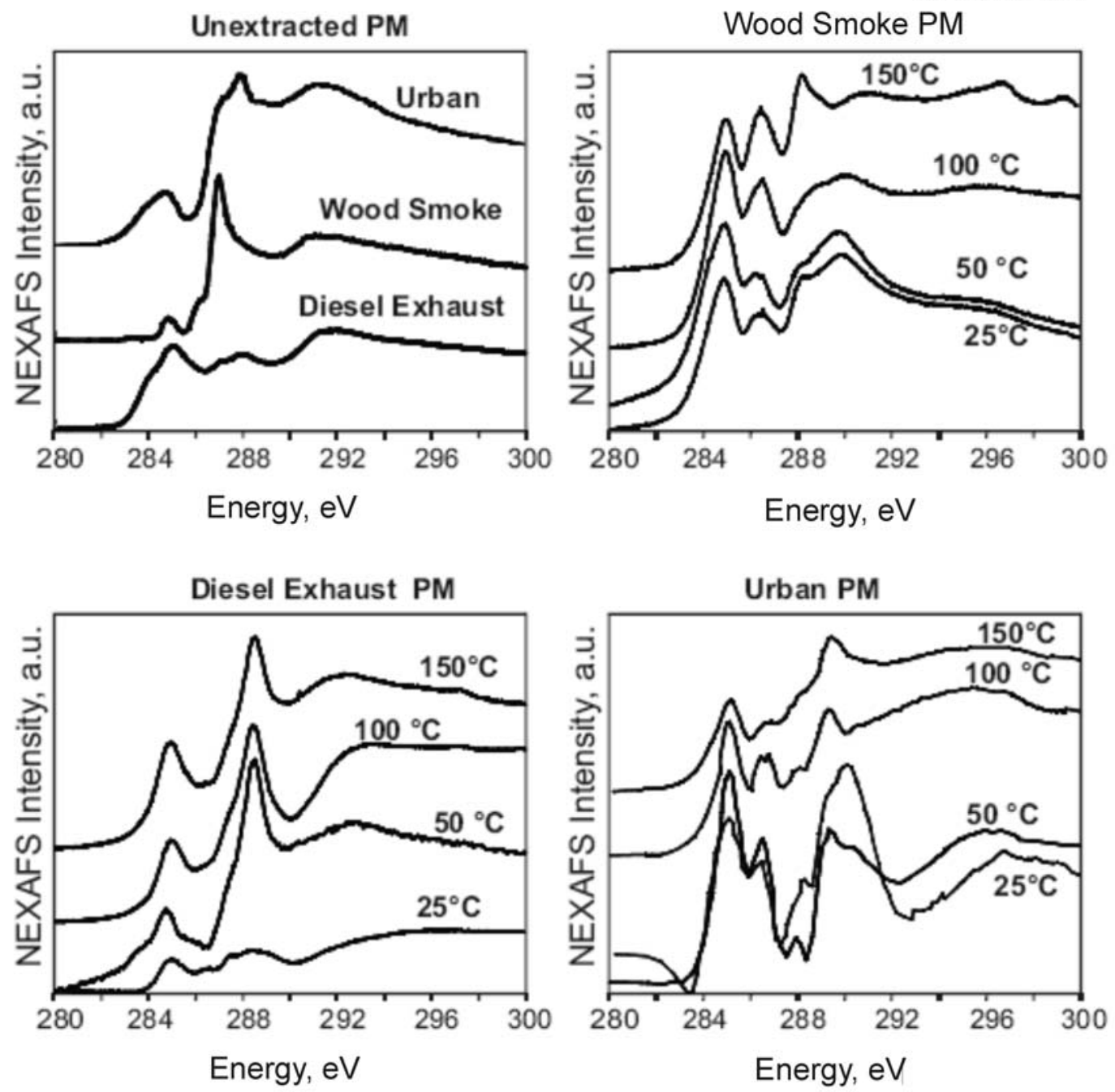

Figure 12. NEXAFS spectra of polar and midpolarity fractions obtained with HPW at different temperatures of PM samples.

Table 3. Inorganics Extracted with Ambient Water (wt\% of PM)

\begin{tabular}{lccc}
\hline & Urban PM & Diesel Exhaust PM & Wood Smoke PM \\
\hline Fluoride & ND $^{\mathrm{a}}$ & ND & ND \\
Chloride & 0.5 & ND & 0.1 \\
Nitrite & ND & ND & ND \\
Bromide & ND & ND & ND \\
Nitrate & 1.0 & ND & ND \\
Phosphate & 0.2 & ND & ND \\
Sulfate & 19 & 0.1 & 1.5 \\
\hline
\end{tabular}

${ }^{a}$ Not detected, the limit of detection was $<0.02 \mathrm{wt} \%$ of initial PM. 
Table 4. Distribution of Sulfate in Fractions Extracted with Hot Pressurized Water

\begin{tabular}{lcccc}
\hline & \multicolumn{4}{c}{ Extraction Temperature } \\
& $25^{\circ} \mathrm{C}$ & $50^{\circ} \mathrm{C}$ & $100^{\circ} \mathrm{C}$ & $150^{\circ} \mathrm{C}$ \\
\hline Urban PM & 19 & 0.9 & 0.8 & 0.5 \\
Diesel Exhaust PM & 0.1 & 0.3 & 0.8 & 0.2 \\
Wood Smoke PM & 1.5 & 0.2 & 0.1 & 0.1 \\
\hline
\end{tabular}

\section{Metal Speciation}

Two different ion chromatographic methods were compared. Both methods were based on the use of a chromatographic column IonPac ${ }^{\mathbb{B}}$ CS5A (Dionex Corporation) suitable for separation of anions and cations at the same time. The mobile phase employed in both methods is based on the formation of anion complexes with pyridine-2-6-dicarboxylic acid. ${ }^{12,17-19}$ Because of higher sensitivity, the derivatization with spectrophotometric postcolumn reagents allowing for the UV-Vis detection was employed.

The first method using 4-2 (2-pyridylazo) resorcinol (PAR) as a derivatizing agent at $535 \mathrm{~nm}$ allowed separation of the following transition metals: $\mathrm{Pb}^{2+}, \mathrm{Fe}^{3+}, \mathrm{Cu}^{2+}, \mathrm{Ni}^{2+}, \mathrm{Co}^{2+}, \mathrm{Cd}^{2+}$, $\mathrm{Mn}^{2+}$, and $\mathrm{Fe}^{2+} \cdot{ }^{17}$ Noticeable on this method is the capability to distinguish divalent and trivalent iron. The detection limit achieved with this method was $100 \mathrm{ppb}$ (using a $250-\mu \mathrm{L}$ loop) for all metals except lead, which was detected at concentrations above $500 \mathrm{ppb}$.

The second method employed 2-[(5-bromo-2-pyridyl)-azo]-5-diethyl-aminophenol (5-BrPADAP) as a derivatizing agent, which allows for sensitive determination of $\mathrm{Pb}^{2+}, \mathrm{Cu}^{2+}, \mathrm{Ni}^{2+}$, $\mathrm{Co}^{2+}, \mathrm{Cd}^{2+}, \mathrm{Mn}^{2+}$, and also $\mathrm{Hg}^{2+} \cdot{ }^{2,18,19}$ The detection limits using this method were $25 \mathrm{ppb}$ for most of the metals.

The methods developed have the potential to be applied for characterization aqueous samples. However, based on the concentrations of metals previously determined, $\sim$ ppb of PM, large samples would be required (e.g., $>1 \mathrm{~g}$ ).

\section{Conclusions}

Within this activity, we developed a method for fractionation of organic carbonaceous PM using hot pressurized water. Hot pressurized water allows for quick inexpensive differentiation of different polarity extractable organic carbon. Thus the technique may be used for carbon assessment in the apportionment studies to differentiate primary (nonpolar) and secondary PM (polar). NEXAFS spectroscopy confirmed the selective extraction of different polarity carbonaceous groups. We have attempted to develop a method for determination of metals in fractions obtained. Unfortunately, the $25 \mathrm{ppb}$ limit of detection does not fall under the concentration range when PM samples of 20-50 mg are extracted. 


\section{References}

1. De Martinis, B.S.; Kado, N.Y.; De Carvalho, L.R.F.; Okamoto, R.A.; Gundel, L.A. Genotoxicity of Fractionated Organic Material in Airborne Particles from Sao Paulo, Brazil. Mutat Res 1999, 446, 83-94.

2. Strandell, M.; Zakrisson, S.; Alsberg, T.; Westerholm, R.; Winquist, L.; Rannug, U. Chemical Analysis and Biological Testing of a Polar Fraction of Ambient Air, Diesel Engine, and Gasoline Engine Particulate Extracts. Environmental Health Perspectives Supplements 1994, 102, 85-92.

3. Grosjean, D. Solvent Extraction and Organic Carbon Determination in Atmospheric Particulate Matter. Organic Extraction-Organic Carbon Analyzer (OE-OCA) Technique. Anal Chem 1975, 47, 797-805.

4. Mazurek, M.A.; Masonjones, M.C.; Masonjones, H.D.; Salmon, L.G.; Cass, G.R.; Hallock, K.A.; Leach, M. Visibility-Reducing Organic Aerosols in the Vicinity of Grand Canyon National Park: Properties Observed by High Resolution Gas Chromatography. J Geophys Res 1997, 102, 3779-3793.

5. Abas, M.R.B.; Simoneit, B.R.T. Composition of Extractable Organic Matter of Air Particles from Malaysia: Initial Study. Atmos Environ 1996, 30, 2779-2723.

6. Kubatova, A.; Steckler, T.S.; Gallagher, J.R.; Hawthorne, S.B.; Picklo, M.J.; Toxicity of Wide-Range Polarity Fractions from Wood Smoke and Diesel Exhaust Particulate Obtained Using Hot Pressurized Water. Environ Toxicol Chem 2004, 23, 2243-2250.

7. Yang, Y.; Hawthorne, S.B.; Miller, D.J. Class-Selective Extraction of Polar, Moderately Polar, and Nonpolar Organics from Hydrocarbon Wastes Using Subcritical Water. Environ Sci Technol 1997, 31, 430-437.

8. Kubatova, A.; Jansen, B.; Vaudoisot, J.F.; Hawthorne, S.B. Thermodynamic and Kinetic Models for the Extraction of Essential Oil from Savory and Polycyclic Aromatic Hydrocarbons from Soil with Hot (subcritical) Water and Supercritical $\mathrm{CO}_{2}$. J Chromatogr A 2002, 975, 175-188.

9. Braun, A.; Shah, N.; Huggins, F.E.; Kelly, K.E.; Sarofim, A.; Jacobsen, C.; Wirick, S.; Francis, H.; Ilavsky, J.; Thomas, G.E. X-Ray Scattering and Spectroscopy Studies on Diesel Soot from Oxygenated Fuel under Various Engine Load Conditions. Carbon 2005, 43, 25882599.

10. Hawthorne, S.B.; Krieger, M.S.; Miller, D.J.; Mathiason, M.B. Collection and Quantification of Methoxylated Phenol Tracers for Atmospheric Pollution from Residential Wood Stoves. Environ Sci Technol 1989, 23, 470-475. 
11. Hawthorne, S.B.; Yang, Y.; Miller, D.J. Extraction of Organic Pollutants from Environmental Solids with Sub- and Supercritical Water. Anal Chem 1994, 66, 2912-2920.

12. Ding, X.J.; Mou, S.F.; Liu, K.N.; Siriraks, A.; Riviello, J. Ion Chromatography of Heavy and Transition Metals by On- and Post-Column Derivatizations. Anal Chim Acta 2000, 407, 319 326.

13. Turpin, B.J.; Saxen, P.; Andrews, E. Measuring and Simulating Particulate Organics in the Atmosphere: Problems and Prospects. Atmos Environ 2000, 34, 2983-3013.

14. Nolte, C.G.; Schauer, J.I.; Cass, G.R.; Simoneit, B.R. Highly Polar Organic Compounds Present in Wood Smoke and in the Ambient Atmosphere. Environ Sci Technol 2001, 35, 1912-1919.

15. Kawamura, K.; Kaplan, I.R. Motor Exhaust Emissions as a Primary Source for Dicarboxylic Acids in Los Angeles Ambient Air. Environ Sci Technol 1987, 21, 105-110.

16. Kubatova, A.; Fernandez, M.M.; Picklo, M.J.; Gallagher, J.R.; Hawthorne, S.B. Initial Results on Use of Subcritical Water for Extraction and Fractionation of Organic Aerosol from Wood Smoke and Diesel Exhaust Particulate and Application Of Toxicity Tests; Arlington, VA, 2002.

17. Siriraks, A.; Kingston, H.M.; Riviello, J.M. Chelation Ion Chromatography as a Method for Trace Elemental Analysis in Complex Environmental and Biological Samples. Anal Chem, 1990, 62, 1185-1193.

18. Lu, H.; Mou, S.; Yan, Y.; Tong, S.; Riviello, J.M. Online Pretreatment and Determination of $\mathrm{Pb}, \mathrm{Cu}$ and $\mathrm{Cd}$ at the mg L-1 level in Drinking Water by Chelation Ion Chromatography. $J$ Chromatogr 1998, 800, 247-255.

19. Nair, L.M.; Saari-Nordhaus, R.; Anderson, J.M., Jr. Ion Chromatographic Separation of Transition Metals on a Polybutadiene Maleic Acid-Coated Stationary Phase. J Chromatogr 1994, 671, 43-49.

\section{Activity 3: Quantum Mechanical Modeling of Mercury Speciation in Coal Combustion Systems and Interactions on Activated Carbon}

\section{Introduction}

Mercury speciation in coal combustion systems is an important area of research, especially as it relates to the control of mercury emissions which is a major concern in coal-fired power industries. The injection of powdered AC into the flue gas stream of coal-fired power plants is currently one of the technologies for controlling mercury emissions. However, the mechanisms of mercury interactions with flue gas components on AC surfaces are complex and rarely understood; consequently, there is considerable research interest on this subject. The EERC has recently developed a model (1) based on extensive experimentation that gives more details about 
the nature of interactions of mercury with $\mathrm{AC}$ and the flue gas components. However, the complexity of the mercury reactions with flue gas components and an AC surface makes it difficult to obtain quantitative measurements for reaction rates, rate constants, and thermodynamic stabilities of reactants, intermediates, transition states, and products. According to the proposed model for the interactions of $\mathrm{Hg}$ on an $\mathrm{AC}$ zigzag edge surface, the following reaction sequence was envisioned:

$$
\begin{aligned}
& \mathrm{R}_{2} \mathrm{C}:+\mathrm{H}^{+} \rightarrow \mathrm{R}_{2} \mathrm{CH}^{+} \\
& \mathrm{R}_{2} \mathrm{CH}^{+}+\mathrm{Hg}(0) \rightarrow\left[\mathrm{R}_{2} \mathrm{CH}-\mathrm{Hg}\right]^{+} \\
& {\left[\mathrm{R}_{2} \mathrm{CH}-\mathrm{Hg}\right]^{+}+\mathrm{X}^{-} \rightarrow \mathrm{R}_{2} \mathrm{CH}-\mathrm{Hg}-\mathrm{X}}
\end{aligned}
$$

where $\mathrm{R}=\mathrm{H}, \mathrm{CH}_{3}$, phenyl, and combinations. A total of six molecules were generated as shown in Figure 13a-f. The desired molecule that was used to represent a carbon zigzag-edge structure, phenalenylidene, is shown in Figure 14.

This project, therefore, was focused on using a theoretical approach to evaluate the $\mathrm{Hg}$ interactions with carbon by the proposed zigzag and armchair carbon graphene-edge structures. Since the computational accessibility of most modern quantum chemical electronic structure methods is limited to small or moderately sized molecules, it was necessary to perform an assessment of existing theoretical methods with the aim to find a suitable theory level to perform computations on the larger coal-mimetic AC prototype molecules. With an appropriate theory level found, the remaining goals of the project were twofold: to determine energy minima on the potential energy surfaces (PESs) of the important structures and to compute quantitative estimates of the relative thermodynamic stabilities of the species, as well as reaction rates and rate constants.

The report is organized as follows. The computational details are given in Section II, and the results are presented and discussed in Section III. Section IV gives the conclusions and future directions.

\section{Methods - Computational Details}

Geometry optimizations followed by calculations of harmonic vibrational frequencies were performed on all reactants, intermediates, and products at the MPW3LYP level. The MPW3LYP variant of DFT is a hybrid generalized gradient approximation DFT developed by Zhao and Truhlar (2) for the purpose of providing a good description of thermochemistry. We used the $6-311+\mathrm{G}(\mathrm{d}, \mathrm{p})(3,4)$ basis set for chlorine atom and the organic moiety and the Stuttgart 1997 (5) effective core potential basis set for the $\mathrm{Hg}$ atom. This combination of basis sets will henceforth be abbreviated as GST97. The choice of MPW3LYP and 6-311+G(d,p) as the theoretical method and basis set for these studies was based on an assessment of theoretical electronic structure methods performed previously (6) on a set of prototype carbene and carbenium ion molecules with sizes ranging from 3 to 26 atoms that were chosen as simple coal-mimetic structures (see Figure 1). The results of the assessment showed that carbene proton attachment energies calculated using the MPW3LYP method with the 6-311+G(d,p) basis set were in close agreement (mean absolute deviation of only 0.003 hartree) with those obtained using G3 
<smiles>[CH]</smiles>

(a) Carbene<smiles>[CH]c1ccccc1</smiles>

(d) Phenylcarbene<smiles>CC=CC</smiles>

(b) Methylcarbene<smiles>CCc1ccccc1</smiles>

(e) Methyl Phenylcarbene
$\mathrm{H}_{3} \mathrm{C}-\mathrm{C}$ :

$\mathrm{CH}_{3}$

(c) Dimethylcarbene<smiles>c1ccc(Cc2ccccc2)cc1</smiles>

(f) Diphenylcarbene

Figure 13. Prototype carbene structures.

EERC SB26797.CDR<smiles></smiles>

Figure 14. Phenalenylidene (g).

theory (7). Equilibrium geometries were compared with those obtained at the MP2/6-311G(d,p) level of theory, and bond lengths and bond angles had a MAD of $0.005 \AA$ and $1.0^{\circ}$, respectively.

Thermal rate constants for the elementary reactions shown in Eqs. 1-3 were calculated at $298.15 \mathrm{~K}$ and 1 atmosphere pressure by the hard-sphere collision theory approximation (8) for all seven carbenes; for a given bimolecular reaction

$$
\mathrm{A}+\mathrm{B} \longrightarrow \mathrm{C}
$$

the thermal rate constant according to the hard-sphere model is given by

$$
k_{A B}=\bar{V}_{A \rightarrow B} \sigma_{A \rightarrow B}^{c},
$$


where $\bar{V}_{A \rightarrow B}=\left(\frac{8 k_{b} T}{\pi \mu_{A B}}\right)^{1 / 2}, \sigma_{A \rightarrow B}^{c}=\pi b_{c o l}^{2}$ and $\mu_{A B}=\frac{m_{A} m_{B}}{m_{A}+m_{B}}$.

$\bar{V}_{A \rightarrow B}$ is the average velocity of A toward B, $\sigma_{A \rightarrow B}^{c}$ is the collision cross section, $\mu_{A B}$ is the

reduced mass of the $\mathrm{AB}$ complex, $k_{b}$ is the Boltzmann constant, $\mathrm{T}$ is the temperature in $\mathrm{K}, \boldsymbol{b}_{\text {col }}$ is the collision diameter, and $m_{A}$ and $m_{B}$ are the masses of $\mathrm{A}$ and $\mathrm{B}$, respectively. All calculations were carried out using Gaussian03 (9), running on a Sun Fire V1280 server (with Sun Ultrasparc III operating system) at the EERC.

\section{Results and Discussion}

The geometrical parameters obtained for the reactants, intermediates and products showed some interesting trends. The general trend was that the $\mathrm{AC}-\mathrm{Hg}$ distance in the organomercurium complexes increased from about $2 \AA$ in the aliphatic compounds to about $4 \AA$ in the grapheneedged prototypes, while in the organomercurychloride compounds, it was consistently about $2 \AA$. Based on the bond length data, it seems suggestive that $\mathrm{Hg}^{0}$ is only partially sorbed (physisorbed) on the AC surface and can be considered fully sorbed (chemisorbed) when the physisorbed complexes are in the presence of $\mathrm{Cl}^{-}$ions. However, just using bond length data alone is not sufficient to draw concrete conclusions because many other factors may be involved.

Thermodynamic data for all the elementary reactions considered (reaction energies $\Delta \mathrm{E}$, enthalpies $\Delta H$, and free energies $\Delta \mathrm{G}$ ) are shown in Figures 15-18. These graphs basically show the variation of these energy quantities with molecule size from small aliphatic prototype molecules to the larger coal-mimetic (graphene-edge type) structures. The calculated energy changes indicate that reaction of carbenes with acidic gas components $\left(\mathrm{HCl}, \mathrm{H}_{2} \mathrm{SO}_{4}\right.$, etc.) to form carbenium ions and the capture of $\mathrm{Cl}^{-}$ions by organomercurium complexes are thermodynamically favorable processes in the proposed mechanistic model (see Figures 14 and 16). The binding energies (BE) and binding constants $(\mathrm{K})$ decrease drastically as the nature of prototype molecules changed from aliphatic side chains to typical aromatic graphene-edge structures (see Figure 17). Corroborating this with bond length trends, it appears to suggest that elemental mercury is chemisorbed on surfaces characterized by aliphatic carbon chains, but it is only physisorbed on surfaces dominated by aromatic structures. This seems to contradict thoughts based on experimental findings that $\mathrm{Hg}^{0}$ is chemisorbed on graphene surfaces, which would mean that reaction of $\mathrm{Hg}^{0}$ with carbenium ions to form organomercurium complexes is not a plausible mechanism as originally proposed (1). But the formation of typically chemisorbed organomercurychloride compounds implies chemisorption on grahene-edge structures, which is if chloride species are present or the reactions would have to occur in a concerted manner. Concerted mechanisms have yet to be investigated computationally for these molecules and can only be the subject of future work. 


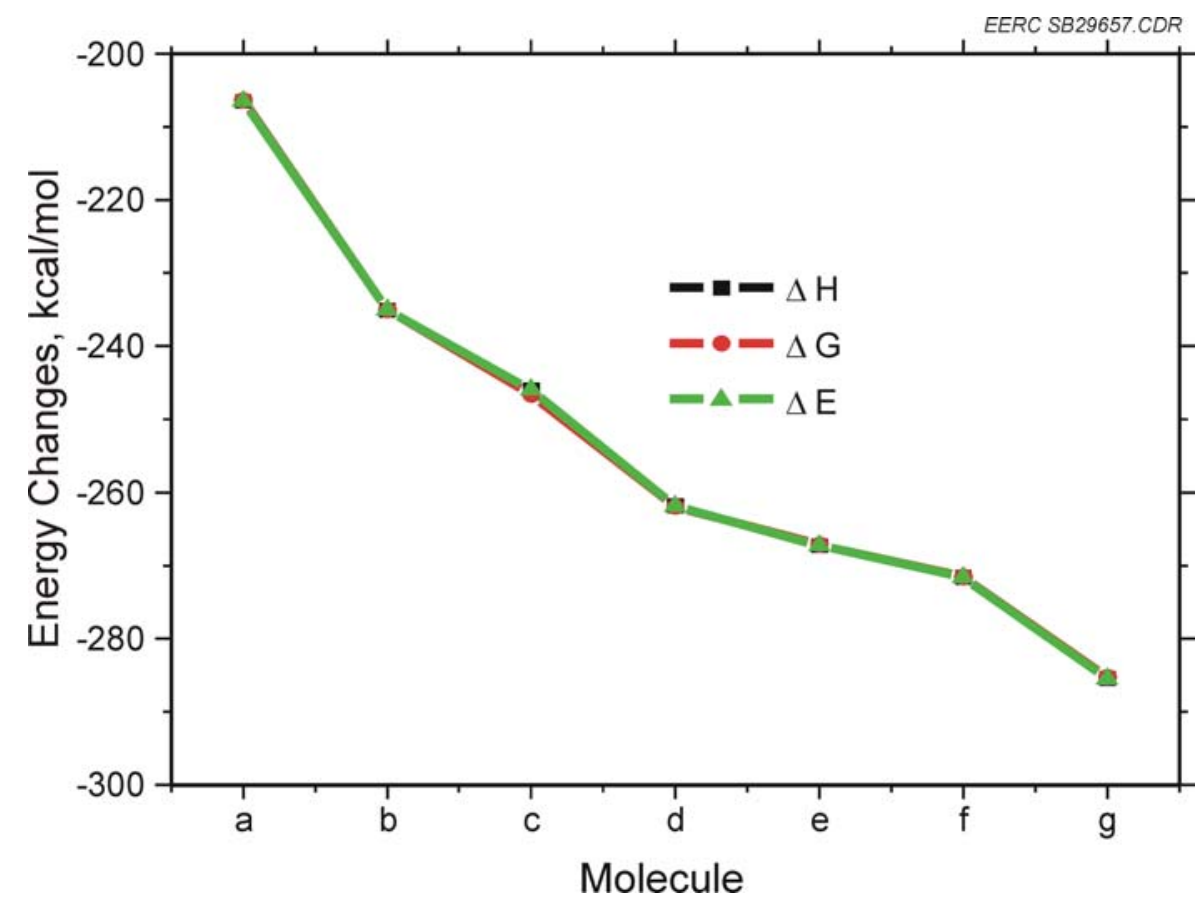

Figure 15. Plot of energy changes for proton attachment with molecule size.

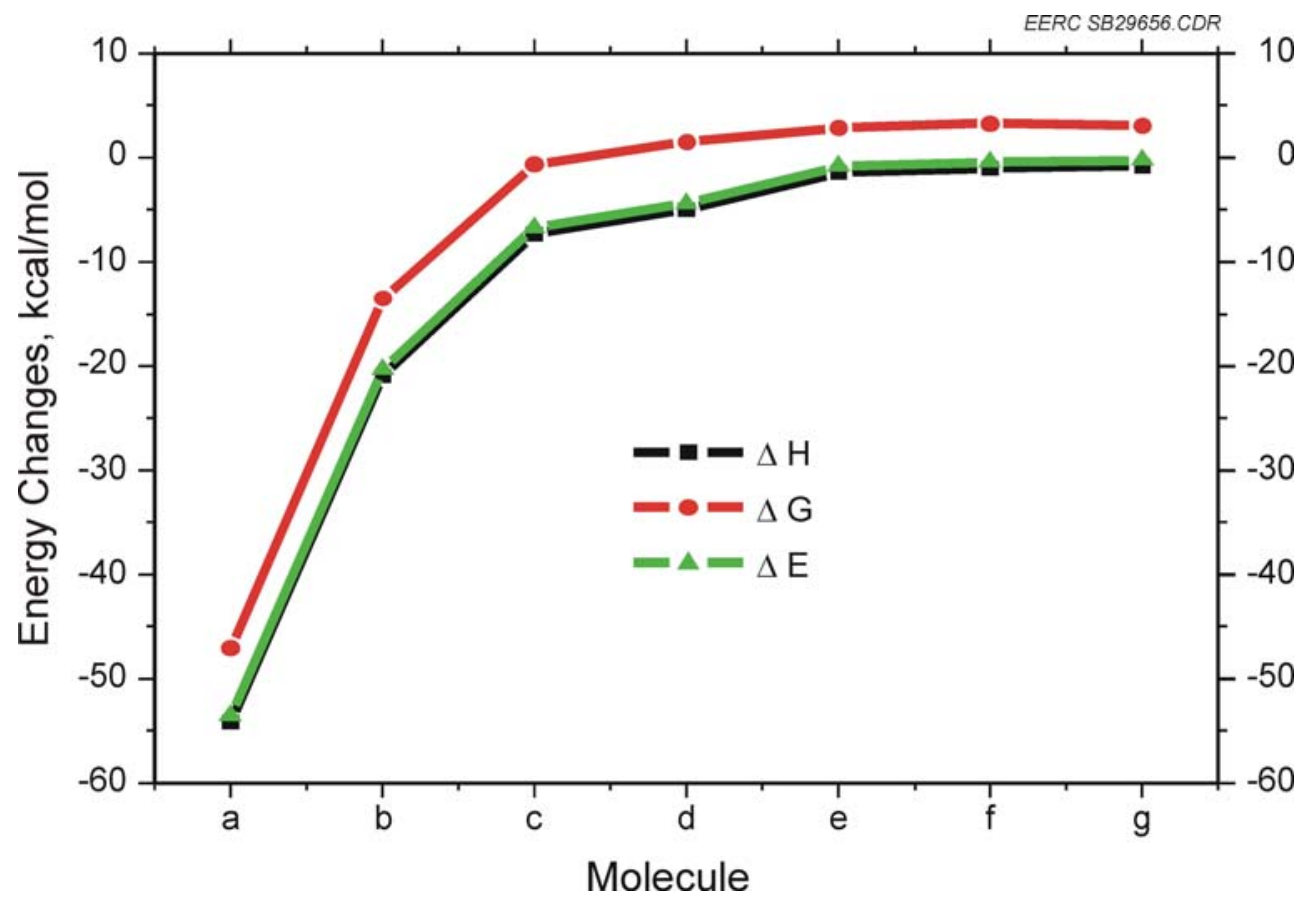

Figure 16. Plot of energy changes for the attachment of $\mathrm{Hg}^{0}$ with molecule size. 


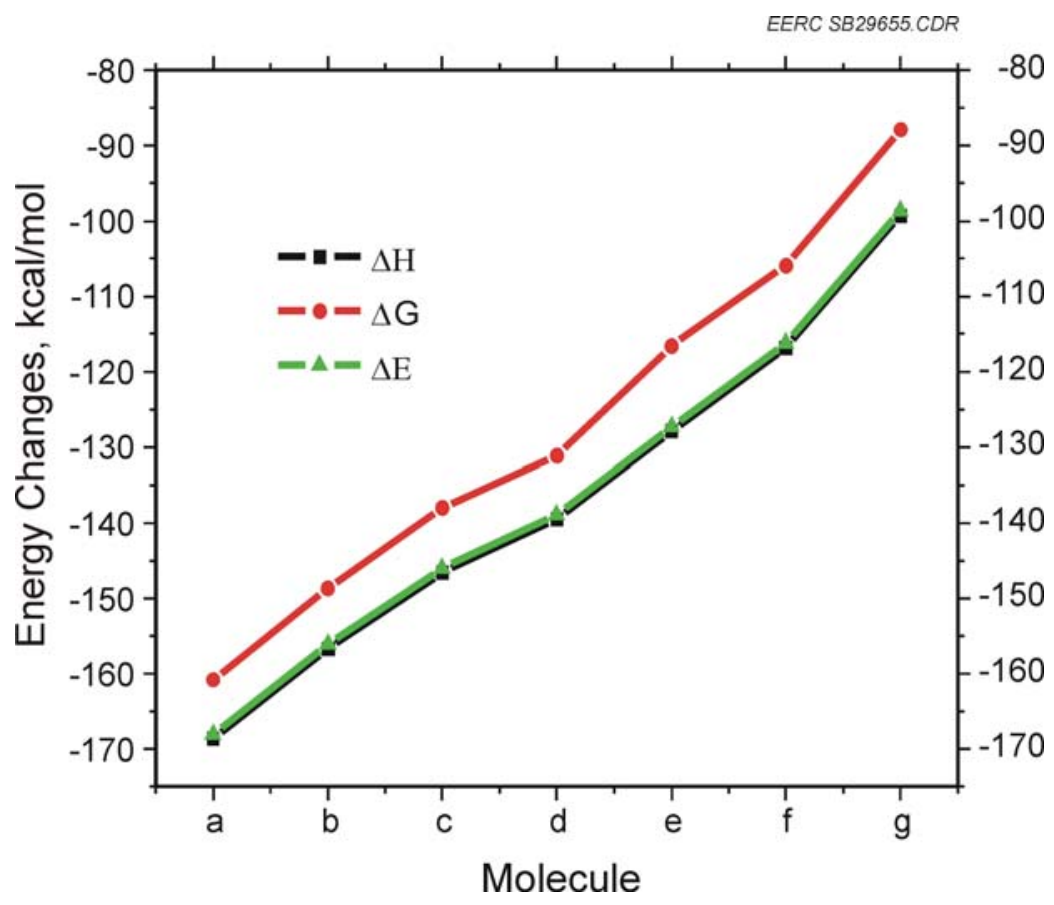

Figure 17. Plot of energy changes for the capture of $\mathrm{Cl}^{-}$with molecule size.

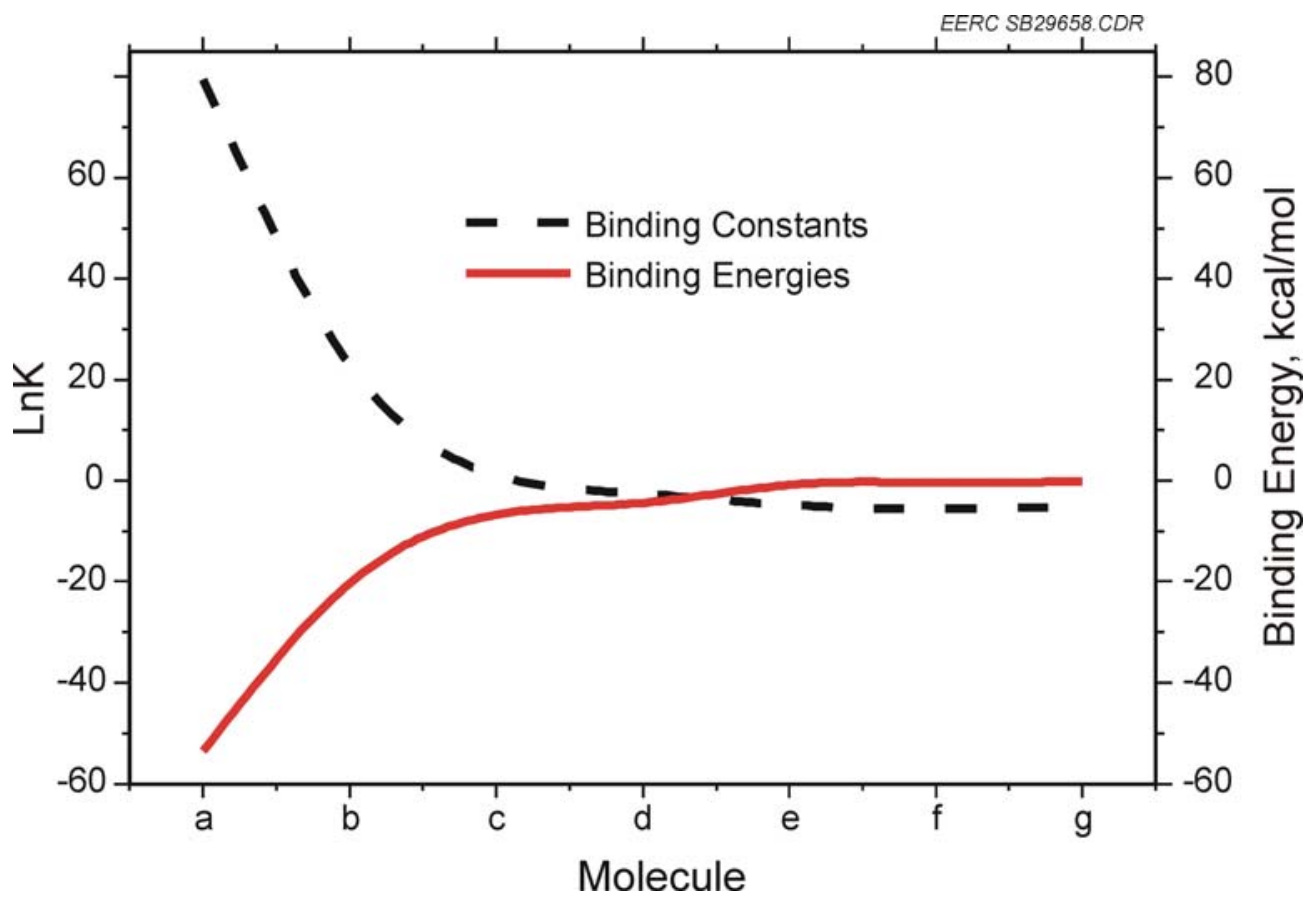

Figure 18. Plot of K, BE with molecule size. 
Kinetic rate constants $(\mathrm{k})$ estimated by the hard-sphere collision theory approximation are shown in Figure 19, plotted against molecule size for the elementary reactions shown in Eqs. $1-3$, designated by Curves I, II, and III, respectively. From these data, one observes that the rates are of the order of $10^{14}$ or $10^{15}$ in some cases. Comparing these with typical Arrhenius prefactors, which are usually in the $10^{13}$ to $10^{14}$ range (10), our results seem to suggest extremely fast kinetics may be involved in these reactions.

\section{Conclusions and Future Directions}

Density functional theory calculations have been carried out in an effort to further elucidate a recently developed mechanistic model for the interactions of $\mathrm{Hg}^{0}$ with flue gas components and prototype activated carbon molecules. Results based on thermodynamic data (free energy, enthalpy, and binding energies) for the elementary reactions on AC surface seem to indicate that predominantly aromatic compounds will suffer a larger energy penalty in oxidizing elemental mercury at room temperature than their aliphatic counterparts. However, AC surface acidification by $\mathrm{HCl}, \mathrm{H}_{2} \mathrm{SO}_{4}$, etc., from the gas stream is a spontaneous process. The organomercurium complexes were found to be stable, although the interactions of $\mathrm{Hg}^{0}$ with prototype graphene-edge structures were rather weak.

Rate constants, estimated using the hard-sphere collision theory approximation, were high, of the order of $10^{14}$ for moderately sized prototypes and $10^{15}$ in the case of the typical grapheneedge prototypes. This appears to indicate that the kinetics of these surface heterogeneous reactions on activated carbon may be very fast and corroborates with the spontaneity of the acidification reactions as predicted by thermodynamic data.

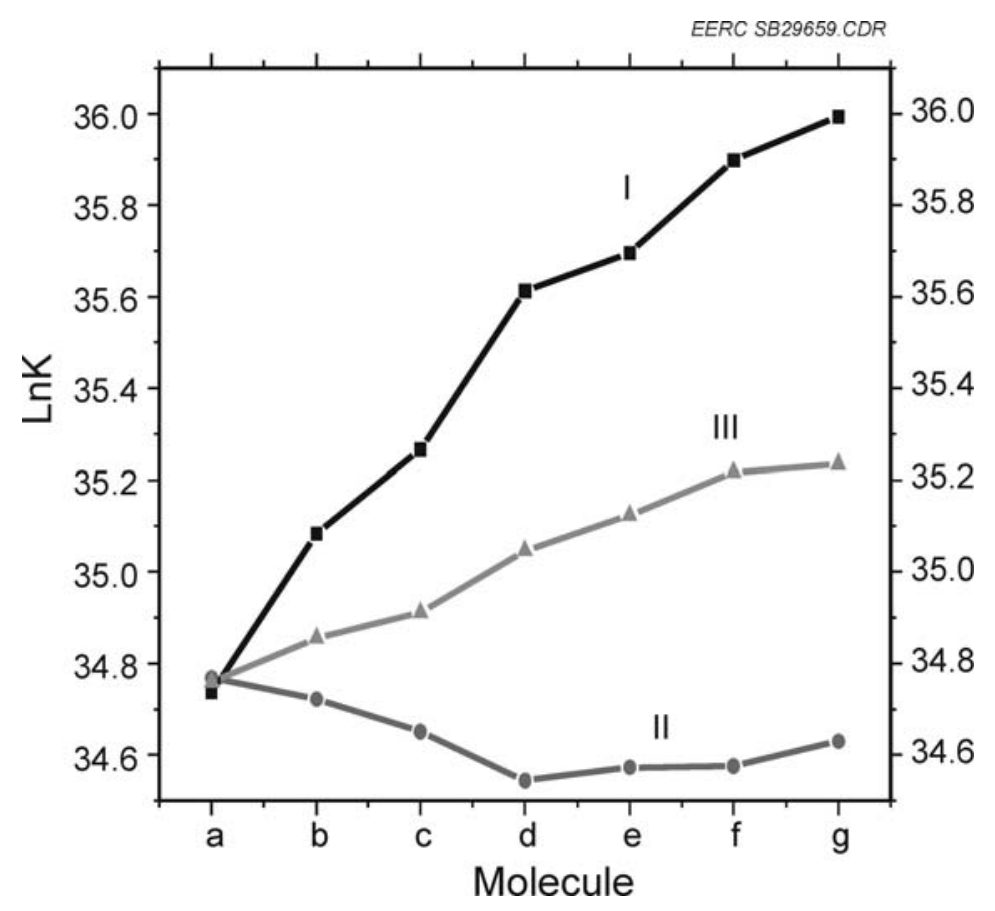

Figure 19. Plot of rate constants with molecule size. 
Future work on this project could possibly explore a little more about the effects of the other halogens besides chlorine, which was used in this study. The thermodynamic conditions could also be modeled closely to the actual experimental conditions by considering higher temperatures and different pressure conditions. Obviously taking into account the effects due to the presence of other flue gas components or exploring other reactive species like free radicals could provide more insight into the nature of mercury interactions on activated carbon surfaces.

\section{References}

1. Olson, E.S.; Laumb, J.D.; Benson, S.A.; Dunham, G.E.; Sharma, R.K.; Mibeck, B.A.; Crocker, C.R.; Miller, S.J.; Holmes, M.J.; Pavlish, J.H. The Mechanistic Model for Flue Gas-Mercury Interactions on Activated Carbons. In Proceedings of the Air Quality IV: Mercury, Trace Elements, and Particulate Matter Conference; Arlington, VA, Sept 22-24, 2003; Paper A5 2.

2. Zhao, Y.; Truhlar, D.G. J. Phys. Chem. A 2004, 108, 6908.

3. Krishnan, R.; Binkley, J.S.; Seeger, R.; Pople, J.A. J. Chem. Phys. 1980, 72, 650.

4. Clark, T.; Chandrasekhar, J.; Schleyer, P.v.R. J. Comp. Chem. 1983, 4, 294.

5. Dolg, M.; Stoll, H.; Preuss, H.; Pitzer, R.M. J. Phys. Chem. 1993, 97, 5852.

6. Azenkeng, A.; Jason, D.L.; Jensen, R.R.; Olson, E.S.; Benson, S.A.; Hoffmann, M.R., Theoretical Electronic Structure Method Computations of Carbene Proton Attachment Energies. 2007, in preparation.

7. Curtiss, L.A.; Raghavachari, K.; Redfern, P.P.; Rassolov, V.; Pople, J.A. J. Chem Phys. 1998, 109, 7764.

8. Venkatesh, R.; Lucchese, R.R.; Marlow, W.H.; Schulte, J. J. Chem. Phys. 1995, 102, 76837699.

9. Frisch, M.J.; Trucks, G.W.; Schlegel, H.B.; Scuseria, G.E.; Robb, M.A.; Cheeseman, J.R.; Montgomery, Jr., J.A.; Vreven, T.; Kudin, K.N.; Burant, J.C.; Millam, J.M.; Iyengar, S.S.; Tomasi, J.; Barone, V.; Mennucci, B.; Cossi, M.; Scalmani, G.; Rega, N.; Petersson, G.A.; Nakatsuji, H.; Hada, M.; Ehara, M.; Toyota, K.; Fukuda, R.; Hasegawa, J.; Ishida, M.; Nakajima, T.; Honda, Y.; Kitao, O.; Nakai, H.; Klene, M.; Li, X.; Knox, J.E.; Hratchian, H.P.; Cross, J.B.; Bakken, V.; Adamo, C.; Jaramillo, J.; Gomperts, R.; Stratmann, R.E.; Yazyev, O.; Austin, A.J.; Cammi, R.; Pomelli, C.; Ochterski, J.W.; Ayala, P.Y.; Morokuma, K.; Voth, G.A.; Salvador, P.; Dannenberg, J.J.; Zakrzewski, V.G.; Dapprich, S.; Daniels, A.D.; Strain, M.C.; Farkas, O.; Malick, D.K.; Rabuck, A.D.; Raghavachari, K.; Foresman, J.B.; Ortiz, J.V.; Cui, Q.; Baboul, A.G.; Clifford, S.; Cioslowski, J.; Stefanov, B.B.; Liu, G.; Liashenko, A.; Piskorz, P.; Komaromi, I.; Martin, R.L.; Fox, D.J.; Keith, T.; Al-Laham, M.A.; Peng, C.Y.; Nanayakkara, A.; Challacombe, M.; Gill, P.M.W.; Johnson, B.; Chen, W.; Wong, M.W.; Gonzalez, C.; Pople, J.A. Gaussian 03, Revision C.02; Gaussian, Inc.: Wallingford, CT, 2004. 
10. Masel, R.I. In Chemical Kinetics and Catalysis; John Wiley \& Sons, Inc.: New York, 2001.

\section{Activity 4: High-Potassium Carbon Production with Biomass-Coal Blending}

\section{Introduction}

The primary objective for this activity was to test the ability for carbons made of highpotassium biomass blended with coal to produce carbon for use in coal-fired flue gases for mercury control. Selection of the materials to be utilized has identified lignite coal from the Center Mine in North Dakota and sunflower hulls for the biomass material to be carbonized. It is hypothesized that the alkali and alkaline-earth elements present in the sunflower hulls as well as the lignite coal may improve mercury capture in the high-sulfur environment of bituminous coalfired flue gases that have been shown to require high levels of carbon injection (5 to $7 \mathrm{lb} / \mathrm{Macf}$ ) to achieve mercury removal. It is known that $\mathrm{SO}_{2}$ (and possibly $\mathrm{SO}_{3}$ ) present in bituminous coalfired flue gases compete for active carbon sorbent sites. This subtask will evaluate the ability of the alkali and alkaline-earth elements present in the biomass-carbon product to react with and remove $\mathrm{SO}_{2}$ and $\mathrm{SO}_{3}$, thereby leaving the carbon sites available for mercury capture.

\section{Methods}

Production of activated carbon from sunflower hull and coal was conducted in a pilot-scale rotary kiln system. A short description of the rotary kiln tube furnace is described below.

\section{Pilot-Scale Rotary-Kiln}

A used Harper International rotary kiln became the center of the rotary kiln system used for pilot-scale activated carbon production. The kiln is a sealed, indirectly electrically heated rotary kiln with a nominal heated zone 6-in. in diameter and 5 feet long, 3-zone temperature control to $1000^{\circ} \mathrm{C}$, inert atmosphere operating conditions, rotation from 1 to $5 \mathrm{rpm}$, internal screw-fed auger, and variable inclination to $5^{\circ}$. The residence time of solids inside the kiln system is determined by a combination of tube rotational speed and tube inclination. The equipment is in turnkey operational condition. The project team designed the emission-handling back end of the system. Figure 20 shows the schematic of the rotary kiln reactor system, and Figure 21 shows the rotary kiln system installed in the EERC pilot plant area.

The gas-handling system runs countercurrently to the coal feed through the kiln. Lifters made of stainless steel were added to the tube interior to improve mixing and gas-solids contact time. The feeders were calibrated with $-1 / 4-$ in. +10 -mesh and -1/8-in. +10 -mesh coal fractions of Hagel Center lignite acquired under a previous project. Terminal velocity calculations to estimate lower-end particle size were performed. Smaller-sized particles could be fed; however, feeding, handling, and dustiness may produce problems. There will presumably be degradation, especially if multiple passes are required to obtain proper residence time and conversion. 


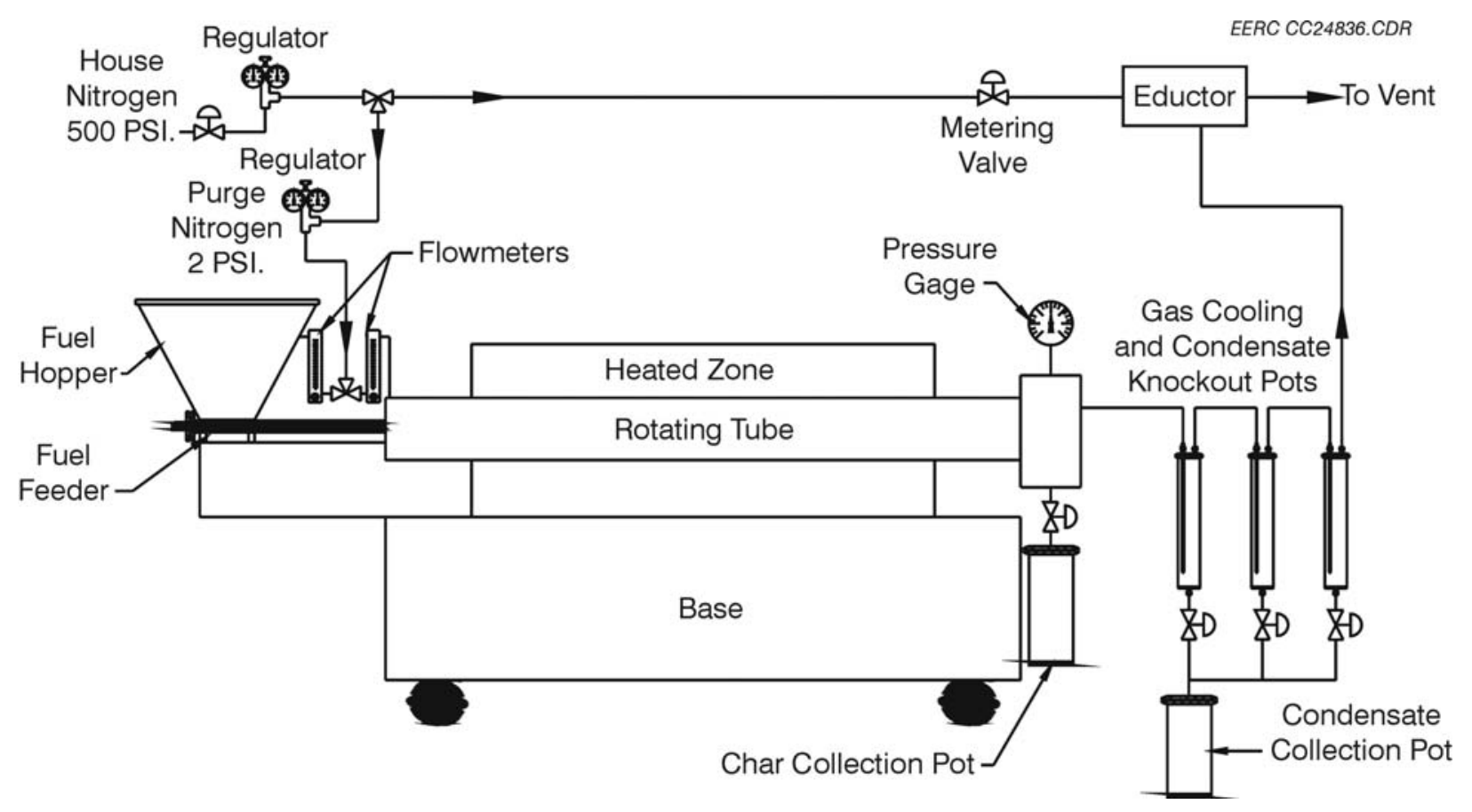

Figure 20. Schematic of the rotary kiln reactor system.

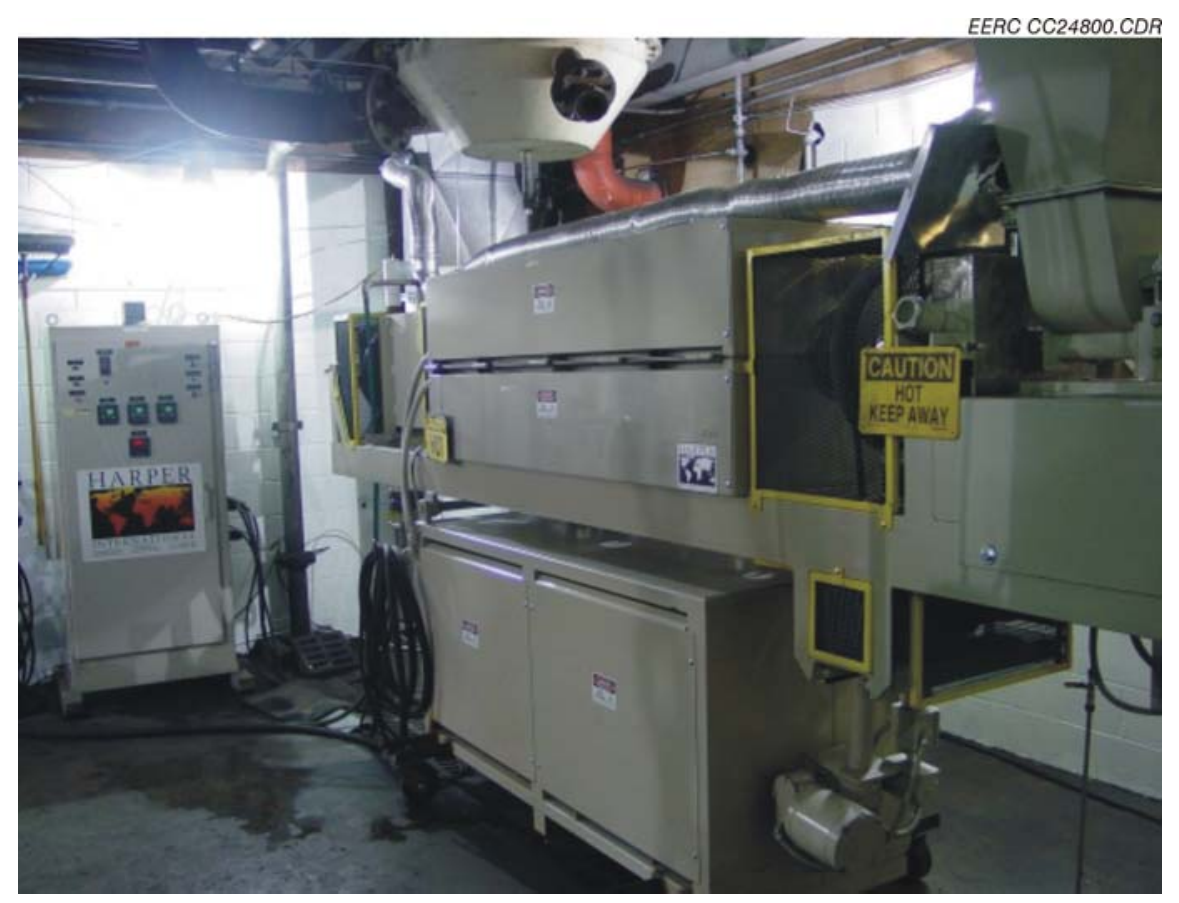

Figure 21. The rotary kiln reactor system installed in the EERC pilot plant. 
The steam generation system is a Sussman MBA6 electric steam generator from Sussman Electric Boilers, Long Island City, New York. The steam generator is rated to produce $18 \mathrm{lb} / \mathrm{hr}$ of steam, with a design pressure of $100 \mathrm{psig}$ and maximum working pressure of $85 \mathrm{psig}$. To superheat the steam generated by the steam generation system, there is a 3-in.-o.d. tube furnace, which has a coil-type heat exchanger.

\section{Mercury Control Testing: Particulate Test Combustor}

A 550,000-Btu/hr pc-fired unit, known as the PTC, was used to test the mercury capture capability of activated carbon produced in a rotary kiln. Figure 22 shows the schematic diagram of the system. Activated carbon was fed with a K-Tron dual-screw feeder upstream of the ESP. The feeder was calibrated prior to the start of carbon injection. In addition, the weight of carbon added during a run was divided by the time of injection to provide an average feed rate. According to the calibration data and weight-of-added-carbon data, the feeder appeared to provide a very steady and consistent feed rate within a few percentage points of the target rate.

Continuous mercury monitors (CMMs) were used to monitor mercury vapor concentrations at the ESP inlet (Site 1) and outlet (Site 2) for the entire testing period.

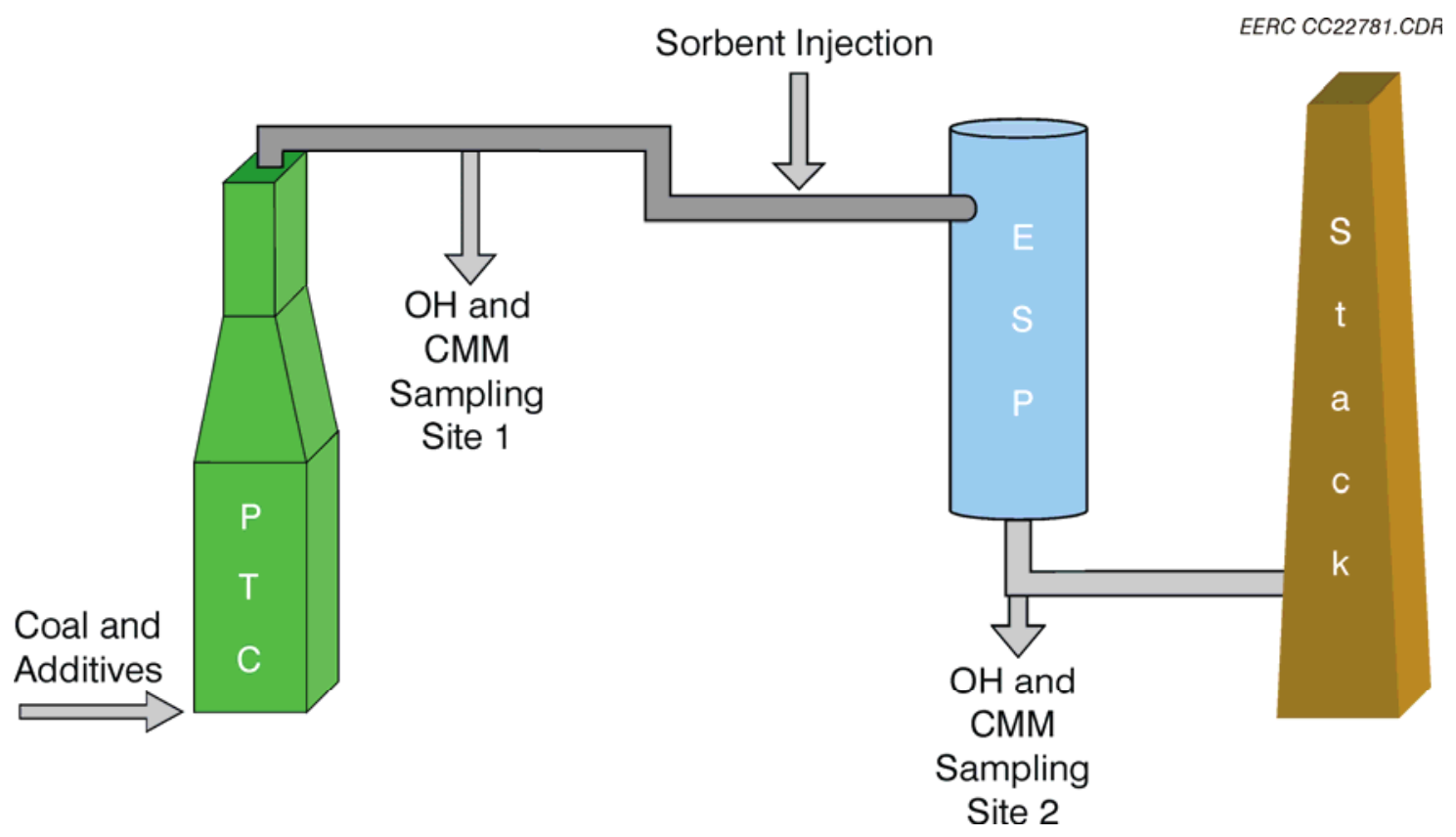

Figure 22. Injection and sampling schematic of the PTC with an ESP. 


\section{RESULTS AND DISCUSSION}

Production of activated carbon was carried out in a pilot-scale rotary kiln system. Carbonization was carried out in the rotary tube furnace, followed by steam activation of the carbonized char for each of the char products. The surface area of the chars and activated carbons was determined by iodine numbers. To determine iodine number, carbons were ground to pass through a 200-mesh sieve. Surface areas (iodine number) were determined using ASTM D 4607. Surface area results of the produced activated carbons were indicative of high-quality carbons.

To investigate the mercury capture capability of the activated carbon produced, pilot-scale mercury capture testing was conducted at the EERC's pilot-scale combustors. Activated carbon was injected into the EERC's PTC flue gas stream to test mercury capture capability of the activated carbon when a high-sulfur Illinois No. 6 coal was fired. Although the activated carbon produced from sunflower hull, Center lignite coal, and hull and coal blend has a high surface area, the mercury capture capability was poor. Further investigations are needed to enhance the mercury capture performance of activated carbon in an Illinois No. 6 coal-derived flue gas. 